nephron

Practice

\title{
UK Renal Registry 17th Annual Report: Chapter 5 Survival and Cause of Death in UK Adult Patients on Renal Replacement Therapy in 2013: National and Centre-specific Analyses
}

\author{
Retha Steenkamp ${ }^{\mathrm{a}}$, Anirudh Rao ${ }^{\mathrm{a}}$, Paul Roderick ${ }^{\mathrm{b}}$ \\ ${ }^{\mathrm{a}}$ UK Renal Registry, Bristol, UK; ${ }^{\mathrm{b}}$ University of Southampton, UK
}

\section{Key Words}

Cause of death - Comorbidity - Dialysis - End stage renal disease - Established renal failure - Haemodialysis - Median life expectancy . Outcome . Peritoneal dialysis - Renal replacement therapy · Survival · Transplant · Vintage

\begin{abstract}
Introduction: The analyses presented in this chapter examine (a) survival from the start of RRT of adult RRT patients; (b) projected life years remaining for adult patients starting RRT; (c) survival amongst prevalent adult dialysis patients alive on 31st December 2012; (d) the death rate in the UK compared to the general population; (e) cause of death for incident and prevalent adult RRT patients. Methods: Survival of incident patients was calculated both from the start of RRT and from 90 days after start. One
\end{abstract}

year survival for prevalent dialysis patients were calculated by following patients up for one year in 2013. The relative risk of death was compared with the general UK population. Results: The age adjusted one year after 90 day survival for patients starting RRT in 2012 was $91.0 \%$ (90.9\% in 2011). Age adjusted one year survival for prevalent dialysis patients remained relatively unchanged at $89.3 \%$ from the previous year. The age-standardised mortality ratio for prevalent RRT patients compared with the general population was 16.2 for age group 35-39 and 2.6 at age 85+ years. In the prevalent RRT dialysis population, cardiovascular disease accounted for $27 \%$ of deaths, infection and other causes for $21 \%$ each and treatment withdrawal for $16 \%$ of deaths. The median life years remaining for a 25-29 year old starting RRT was 18.5 years and approximately 2.4 years for a $75+$ year old. Conclusions: Survival of patients starting RRT has improved substantially in last decade, overall, by age and for diabetic patients. 


\section{Introduction}

The analyses presented in this chapter examine a) survival from the start of RRT of adult patients; $b$ ) projected life years remaining for adult patients starting RRT; c) survival amongst prevalent adult dialysis patients alive on 31st December 2012; d) the death rate in the UK compared to the general population; e) the cause of death for incident and prevalent adult patients. They encompass the outcomes from the total incident adult UK dialysis population (2012) reported to the UK Renal Registry (UKRR), including the $19.6 \%$ who started on peritoneal dialysis and the $7.5 \%$ who received a preemptive renal transplant. These results are therefore a true reflection of the outcomes in the whole UK adult incident RRT population. Analyses of survival within the first year of starting RRT include patients who were recorded as having started RRT for established renal failure (as opposed to acute kidney injury) but who had died within the first 90 days of starting RRT, a group excluded from most other countries' registry data. As is common in other countries, survival analyses are also presented for the first year after 90 days.

The term established renal failure (ERF) used throughout this chapter is synonymous with the terms end stage renal failure (ESRF) and end stage renal disease (ESRD) which are in more widespread international usage. Within the UK, patients have disliked the term 'end stage'; the term ERF was endorsed by the English National Service Framework for Renal Services, published in 2004.

Since 2006, the UKRR has openly reported and published centre attributable RRT survival data. It is again stressed that these are raw data which continue to require very cautious interpretation. The UKRR can adjust for the effects of the different age distributions of patients in different centres, but lacks sufficient data from many participating centres to enable adjustment for primary renal diagnosis, other comorbidities at start of RRT (age and comorbidity, especially diabetes, are major factors associated with survival [1-3]) and ethnic origin, which have been shown to have an impact on outcome (for instance, better survival is expected in centres with a higher proportion of Black and South Asian patients) [4]. This lack of information on case-mix makes interpretation of any apparent difference in survival between centres and UK countries difficult. Despite the uncertainty about any apparent differences in outcome, for centres which appear to be outliers the UKRR will follow the clinical governance procedures as set out in chapter 2 of the 2009 UKRR Report [5].

\section{Methods}

The unadjusted survival probabilities (with 95\% confidence intervals) were calculated using the Kaplan-Meier method, in which the probability of surviving more than a given time can be estimated for all members of a cohort of patients overall or by subgroup such as age group, but without any adjustment for confounding factors such as age that affect the chances of survival. Where centres are small, or the survival probabilities are greater than $90 \%$, the confidence intervals are only approximate.

In order to estimate the difference in survival of different subgroups of patients within the cohort, a stratified proportional hazards model (Cox) was used where appropriate. The results from the Cox model were interpreted using a hazard ratio. When comparing two groups, the hazard ratio is the ratio of the estimated hazard for group A relative to group B, where the hazard is the risk of dying at time $t$ given that the individual has survived until this time. The underlying assumption of a proportional hazards model is that the hazard ratio remains constant throughout the period under consideration. Whenever used, the assumptions of the proportional hazards model were tested.

To allow comparisons between centres with differing age distributions, survival analyses were statistically adjusted for age and reported as survival adjusted to age 60 . This gives an estimate of what the survival would have been if all patients in that centre had been aged 60 at the start of RRT. This age was chosen because it was approximately the average age of patients starting RRT 15 years ago at the start of the UKRR's data collection. The average age of patients commencing RRT in the UK has recently stabilised around an age of 62 years, but the UKRR has maintained age adjustment to 60 years for comparability with all previous years' analyses. Diabetic patients were included in all analyses unless stated otherwise and for some analyses, diabetic and non-diabetic patients were analysed separately and compared. Non-diabetic patients were defined as all patients excluding those patients with diabetes as the primary renal disease. All analyses were undertaken using SAS 9.3.

Centre variability for incident and prevalent patient survival was analysed using a funnel plot. For any number of patients in the incident cohort ( $\mathrm{x}$-axis), one can identify whether any given survival probability (y-axis) falls within, plus or minus 2 standard deviations (SDs) from the national mean (solid lines, 95\% limits) or 3SDs (dotted lines, $99.9 \%$ limits).

\section{Definition of RRT start date}

The incident survival figures quoted in this chapter are from the first day of RRT whether with dialysis or a pre-emptive transplant. In the UKRR all patients starting RRT for ERF are included from the date of the first RRT treatment wherever it took place (a date currently defined by the clinician) if the clinician considered the renal failure irreversible. Should a patient recover renal function within 90 days they were then excluded. These UK data therefore may include some patients who died within 90 days who had developed acute potentially reversible renal failure but were recorded by the clinician as being in irreversible established renal failure.

Previously, the UKRR asked clinicians to re-enter a code for established renal failure in patients initially coded as having acute renal failure once it had become clear that there was no 
recovery of kidney function. However, adherence to this requirement was very variable, with some clinicians entering a code for established renal failure only once a decision had been made to plan for long-term RRT [6]. All UK nephrologists have now been asked to record the date of the first haemodialysis session and to record whether the patient was considered to have acute kidney injury (acute renal failure) or to be in ERF at the time. For patients initially categorised as 'acute', but who were subsequently categorised as ERF, the UKRR assigns the date of this first 'acute' session as the date of start of RRT.

UKRR analyses of electronic data extracted for the immediate month prior to the start date of RRT provided by clinicians highlighted additional inconsistencies in the definition of this first date when patients started on peritoneal dialysis, with the date of start reported to the UKRR being later than the actual date of start. These findings are described in detail in chapter 13 of the 2009 Report [6]. This concern is unlikely to be unique to the UK, but will be common to analyses from all renal centres and registries.

In addition to these problems of defining day 0 within one country, there is international variability on when patient data are collected by national registries with some countries (often for financial re-imbursement or administrative reasons) defining the 90th day after starting RRT as day 0, whilst others collect data only on those who have survived 90 days and report as zero the number of patients dying within the first 90 days.

Thus as many other national registries do not include reports on patients who do not survive the first 90 days, survival from 90 days onwards is also reported to allow international comparisons. This distinction is important, as there is a much higher death rate in the first 90 days, which would distort comparisons.

\section{Methodology for incident patient survival}

The incident population is defined as all patients over 18 years old who started RRT at UK renal centres and did not have a recovery lasting more than 90 days within 90 days of starting RRT. Patients were considered 'incident' at the time of their first RRT, thus patients re-starting dialysis after a failed transplant were not included in the incident cohort (see appendix B:1 for a detailed definition of the incident (take-on) population).

For incident survival analyses, patients newly transferred into a centre who were already on RRT were excluded from the incident population for that centre and were counted at the centre at which they started RRT. Some patients recover renal function after more than 90 days but subsequently returned to RRT. If recovery was for less than 90 days, the start of RRT was calculated from the date of the first episode and the recovery period ignored. If recovery was for 90 days or more, the length of time on RRT was calculated from the day on which the patient restarted RRT.

The incident survival cohort was NOT censored at the time of transplantation and therefore included the survival of the $7.5 \%$ who received a pre-emptive transplant. An additional reason for not censoring was to facilitate comparison between centres. Centres with a high proportion of patients of South Asian and Black origin are likely to have a healthier dialysis population, because South Asian and Black patients are less likely to undergo early transplantation [7], and centres with a high pre-emptive transplant rate are likely to have a less healthy dialysis population as transplantation selectively removes fit patients only. However censoring at transplantation was performed in the 1997-2012 cohort to establish the effect on long term survival by age group and also in the 2009-2012 cohort to investigate the effect on the outlying status of centres.

The one year incident survival is for patients who started RRT from 1st October 2011 until the 30th September 2012 and followed up for one full year (e.g. patients starting RRT on 1st December 2011 were followed through to 30th November 2012). The 2013 incident patients could not be analysed as they had not yet been followed for a sufficient length of time. For analysis of one year after 90 day survival, patients who started RRT from 1st October 2011 until 30th September 2012 were included in the cohort and they were followed up for a full one year after the first 90 days of RRT.

Two year's incident data (2011-2012) were combined to increase the size of the patient cohort, so that any differences between the four UK countries can likely be more reliably identified. To help identify any centre differences in survival from the small centres (where confidence intervals are large), an analysis of one year after 90 day survival using a rolling four year combined incident cohort from 2009 to 2012 was also undertaken. For those centres which had joined the UKRR after 2009, data were not available for all the years but the available data were included. A 10 year rolling cohort was used when analysing trends over time and for long term survival, a cohort from 1997 to 2012 was analysed.

The death rate per 1,000 patient years was calculated by dividing the number of deaths by the person years exposed. Person years exposed are the total years at risk for each patient (until death, recovery or lost to follow up). The death rate is presented by age group and UK nation.

Adjustment of one year after 90 day survival for the effect of comorbidity was undertaken using a rolling four year combined incident cohort from 2009 to 2012. Twenty-four centres returned $\geqslant 85 \%$ of comorbidity data for patients in the combined cohort. Adjustment was first performed to a mean age of 60 years, then to the average distribution of primary renal diagnoses for the 24 centres. The individual centre data were then further adjusted for average distribution of comorbidity present at these centres.

\section{Methodology of median life expectancy}

Kaplan Meier survival analyses were used to calculate the median survival after the first 90 days by age group (18-34, 35$44,45-54,55-64,65-74,75+)$ for incident patients starting RRT from 2001-2010, with at least three years follow up from 2011 to 2013. The patient inclusion criteria are the same as those of the incident patient cohort described above. Patients were followed until death, censoring (recovery or lost to follow up) or the end of the study period. Median life years remaining is the difference between the age when reaching the $50 \%$ probability of survival and the age of starting RRT. Median life years remaining were calculated for all incident and diabetic incident patients

\section{Methodology for prevalent dialysis patient survival}

The prevalent dialysis patient group was defined as all patients over 18 years old, alive and receiving dialysis on 31st December 2012 who had been on dialysis for at least 90 days at one of the UK adult renal centres. Prevalent dialysis patients on 31 st December 2012 were followed-up in 2013 and were censored at transplantation. When a patient is censored at transplantation, this means that the patient is considered as alive up to the point of 
transplantation, but the patient's status post-transplant is not considered.

As discussed in previous reports, comparison of survival of prevalent dialysis patients between centres is complex. Survival of prevalent dialysis patients can be studied with or without censoring at transplantation and it is common practice in some registries to censor at transplantation. Censoring could cause apparent differences in survival between those renal centres with a high transplant rate and those with a low transplant rate, especially in younger patients where the transplant rate is highest. Censoring at transplantation systematically removes younger fitter patients from the survival data. The differences are likely to be small due to the relatively small proportion of patients being transplanted in a given year compared to the whole dialysis population (about 14\% of the dialysis population aged under 65 and 2\% of the population aged 65 years and over). To allow comparisons with other registries the survival results for prevalent dialysis patients CENSORED for transplantation have been quoted. To understand survival of patients, including survival following transplantation, the incident patient analyses should be viewed. The effect of not censoring at transplantation was performed in the 2012 cohort to investigate the effect on the outlying status of centres.

Methodology for comparing mortality in prevalent $R R T$ patients with the mortality in the general population

Data on the UK population in mid-2013 and the number of deaths in each age group in 2013 were obtained from the Office of National Statistics. The age specific UK death rate was calculated as the number of deaths in the UK per thousand people in the population. The age specific expected number of deaths in the RRT population was calculated by applying the UK age specific death rate to the total of years exposed for RRT patients in that age group. This is expressed as deaths per 1,000 patient years. The age specific number of RRT deaths is the actual number of deaths observed in 2013 in RRT patients. The RRT observed death rate was calculated as number of deaths observed in 2013 per 1,000 patient years exposed. Relative risk of death was calculated as the ratio of the observed and expected death rates for RRT patients. The death rate was calculated for the UK general population by age group and compared with the same age group for prevalent patients on RRT on 31st December 2012.

\section{Methodology of cause of death}

The EDTA-ERA Registry codes for cause of death were used. These have been grouped into the following categories:

- Cardiac disease

- Cerebrovascular disease

- Infection
- Malignancy

- Treatment withdrawal

- Other

- Uncertain

Completeness of cause of death data was calculated for all prevalent patients on RRT that died in a specific year with cause of death data completed for that year. Patients that were lost to follow up or that recovered were not included in the cause of death completeness calculation.

Adult patients aged 18 years and over from England, Wales, Scotland and Northern Ireland were included in the analyses of cause of death. The incident patient analysis included all patients starting RRT in the years 2000-2012. Analysis of prevalent patients included all those aged over 18 years and receiving RRT on 31st December 2012 and followed-up for one year in 2013.

\section{Results \\ Incident (new RRT) patient survival}

\section{Overall survival}

The 2012 incident cohort included 6,881 patients who started RRT, without any period of renal function recovery lasting more than 90 days. The age adjusted (adjusted to age 60) one year after 90 day survival for incident patients starting RRT in 2012 (table 5.1), was similar to last year: $91.0 \%$ compared to $90.9 \%$ in the 2011 cohort. Survival at 90 days was also similar to the 2011 cohort at $96.2 \%$ (table 5.1 ).

\section{Survival by UK country}

There was no evidence of a difference in the 90 day survival between the UK countries (table 5.2). One year after 90 day survival in Wales decreased to $86.6 \%$ from $88.2 \%$ in the previous cohort (2010-2011) and although there was evidence that survival was lower compared to England, Northern Ireland and Scotland (table 5.2), this data have not been adjusted for differences in primary renal diagnosis, ethnicity, socio-economic status or comorbidity, nor for differences in life expectancy in the general populations of the four UK countries. There are known regional differences in the life expectancy of

Table 5.1. Survival of incident patients, 2012 cohort

\begin{tabular}{lcccc}
\hline Interval & $\begin{array}{c}\text { Unadjusted } \\
\text { survival } \\
(\%)\end{array}$ & $\begin{array}{c}\text { Adjusted } \\
\text { survival } \\
(\%)\end{array}$ & $95 \% C I$ & $N$ \\
\hline Survival at 90 day & 94.5 & 96.2 & $95.6-96.7$ & 6,881 \\
Survival one year after 90 days & 88.0 & 91.0 & $90.2-91.8$ & 6,484 \\
\hline
\end{tabular}


Table 5.2. Incident patient survival across the UK countries, combined 2 year cohort (2011-2012), adjusted to age 60

\begin{tabular}{|c|c|c|c|c|c|}
\hline Interval & England & $\mathrm{N}$ Ireland & Scotland & Wales & UK \\
\hline $95 \%$ CI & $95.8-96.6$ & $94.9-97.9$ & $94.9-97.0$ & $95.5-97.6$ & $95.8-96.6$ \\
\hline $95 \%$ CI & $90.6-91.8$ & $89.2-94.0$ & $89.2-92.5$ & $84.4-88.8$ & $90.3-91.5$ \\
\hline
\end{tabular}

the general population within the UK. Table 5.3 shows differences in life expectancy between the UK countries for the period 2010-2012. These differences in life expectancy are not accounted for in these analyses and are likely to be one of the reasons contributing to the variation in survival between renal centres and UK countries.

\section{Survival by modality}

It is impossible to obtain truly valid comparisons of survival of patients starting RRT on different treatment modalities, as modality selection is not random. In the UK, patients starting peritoneal dialysis as a group were younger and fitter than those starting haemodialysis and were transplanted more quickly. The age adjusted one year survival estimates for incident patients starting

Table 5.3. Life expectancy in years in UK countries, 2010-2012 (source ONS [8])

\begin{tabular}{lccccc}
\hline \multirow{2}{*}{ Country } & \multicolumn{2}{c}{ At birth } & & \multicolumn{2}{c}{ At age 65 } \\
\cline { 2 - 3 } \cline { 5 - 6 } \cline { 5 - 6 } & Male & Female & & Male & Female \\
\hline England & 79.2 & 83.0 & & 18.6 & 21.1 \\
Northern Ireland & 77.8 & 82.3 & & 17.9 & 20.6 \\
Scotland & 76.6 & 80.8 & & 17.2 & 19.5 \\
Wales & 78.2 & 82.8 & & 18.0 & 20.6 \\
UK & $\mathbf{7 8 . 9}$ & $\mathbf{8 2 . 7}$ & & $\mathbf{1 8 . 4}$ & $\mathbf{2 0 . 9}$ \\
\hline
\end{tabular}

RRT on $\mathrm{HD}$ and PD were $89.2 \%$ and $93.7 \%$ respectively, with PD patient survival increasing by $0.8 \%$ from the previous year (figure 5.1). Over the last 10 years the one year after 90 days survival has progressively improved in HD patients, but remained static in $\mathrm{PD}$ patients (figure 5.1).

\section{Survival by age}

Tables 5.4 and 5.5 show survival of all incident patients, those aged $\geqslant 65$ years and those aged $<65$

Table 5.4. Unadjusted 90 day survival of incident patients, 2012 cohort, by age

\begin{tabular}{lccc}
\hline Age group & Survival (\%) & $95 \%$ CI & $N$ \\
\hline $18-64$ & 97.5 & $96.9-98.0$ & 3,541 \\
$\geqslant 65$ & 91.3 & $90.3-92.2$ & 3,340 \\
All ages & 94.5 & $93.9-95.0$ & 6,881 \\
\hline
\end{tabular}

Table 5.5. Unadjusted one year after day 90 survival of incident patients, 2012 cohort, by age

\begin{tabular}{lccc}
\hline Age group & Survival (\%) & $95 \%$ CI & $N$ \\
\hline $18-64$ & 93.8 & $93.0-94.6$ & 3,444 \\
$\geqslant 65$ & 81.3 & $79.8-82.6$ & 3,040 \\
All ages & 88.0 & $87.1-88.7$ & 6,484 \\
\hline
\end{tabular}

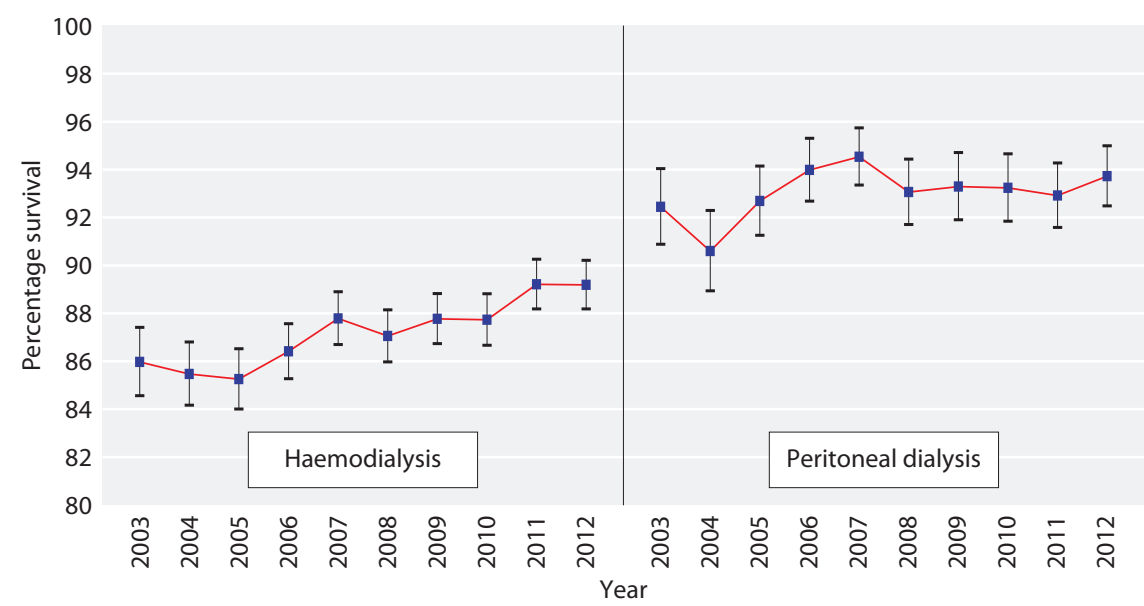

Fig. 5.1. Trend in one year after 90 day incident patient survival by first modality, 2003-2012 cohorts (adjusted to age 60) (excluding patients whose first modality was transplantation) 


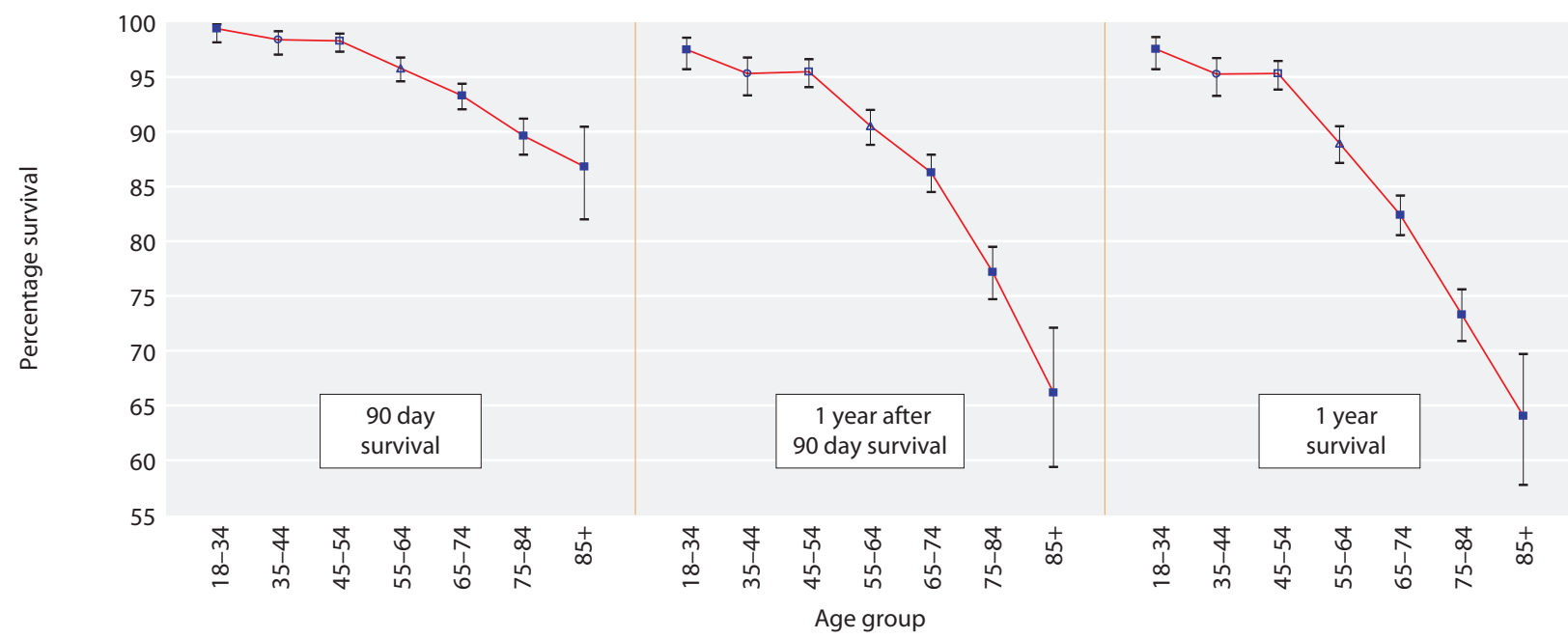

Fig. 5.2. Unadjusted survival of incident patients by age group, 2012 cohort

years. In the UK, short term survival (survival at 90 days) remains static at $94.5 \%$ (table 5.4). Survival one year after 90 days increased marginally compared to last year $(87.5 \%)$ and this was mainly due to an increase in survival for patients aged $\geqslant 65$ years (table 5.5 ). There was a steep decline in survival with advancing age (figures 5.2 and 5.3).

There was a curvilinear increase in death rate per 1,000 patient years with age for the period one year after 90 days (figure 5.3). There was evidence that the overall death rate in Wales was higher than in the other UK countries, mostly due to a higher death rate in Wales for older patients ( $\geqslant 65$ years old) (figure 5.3). There was also evidence that the one year prevalent dialysis patient death rate in the 2012 cohort was higher in Wales compared to England.

From figure 5.4 it can be seen that $50 \%$ of patients starting RRT aged between 45-54 survived for over 10 years, $50 \%$ of patients starting RRT aged between

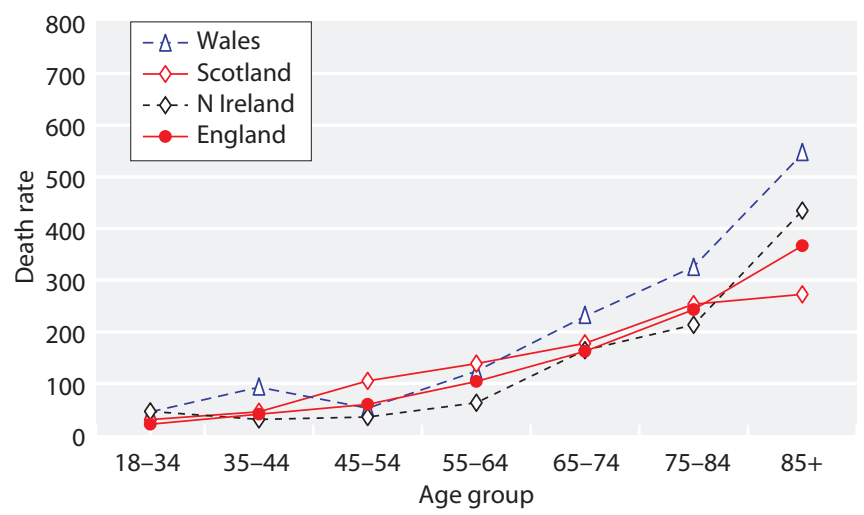

Fig. 5.3. One year after 90 days death rate per 1,000 patient years by UK country and age group for incident patients, 2009-2012 cohort

55-64 survived for about 5.8 years and $50 \%$ of patients starting RRT aged between 65-74 survived for about 3.4 years (also see also median life expectancy on RRT).

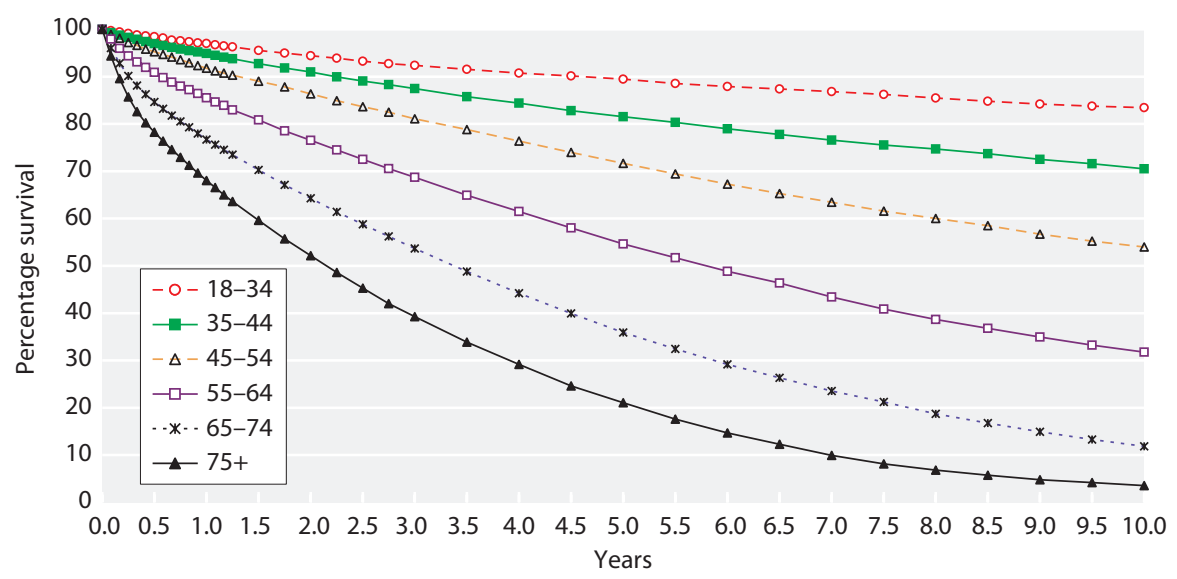

Fig. 5.4. Survival of incident patients (unadjusted), 1997-2012 cohort (from day 0 ), without censoring at transplantation 


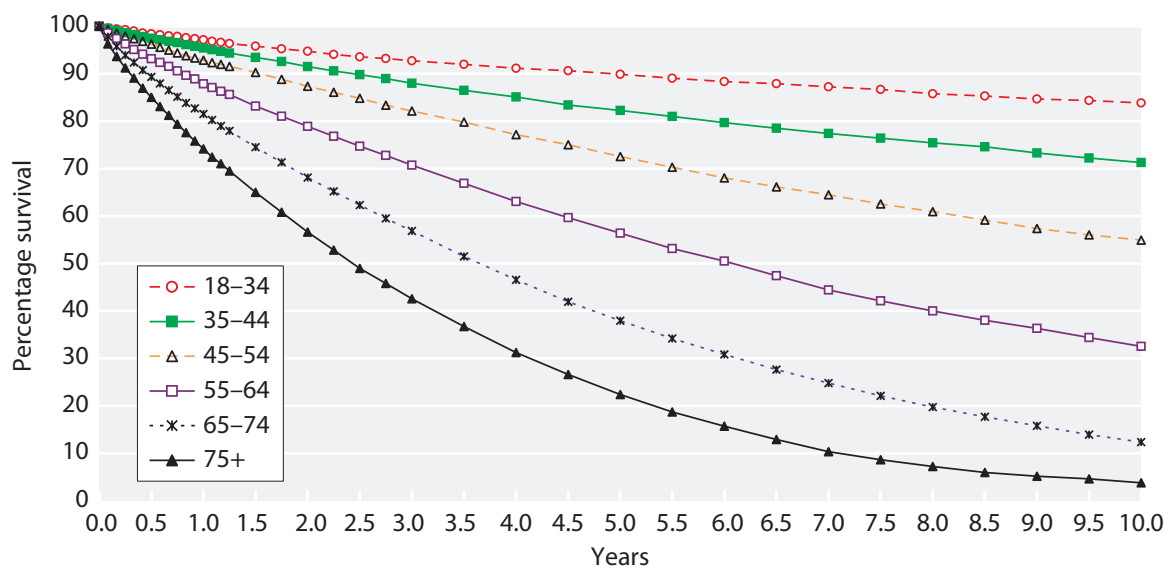

Fig. 5.5. Survival of incident patients (unadjusted), 1997-2012 cohort (from day 90), without censoring at transplantation
Figure 5.5 illustrates the survival of incident patients, without censoring at transplantation and shows that $50 \%$ of patients aged between 55-64 years survived for 6 years and $50 \%$ of patients aged between $65-74$ years survived for about 3.6 years.

Censoring at transplantation would make the longer term outcomes of younger patients (who were more likely to have undergone transplantation) appear worse than they actually were. Without censoring, the 10 year survival for patients aged 18-34 years was $83.4 \%$ (figure 5.4), which contrasts with a $56.9 \%$ survival if censoring at the time of transplantation (data not shown). For more detailed information on this effect, refer to the 2008 Report [9].

\section{Age and the hazard of death}

Figure 5.6 shows the monthly hazard of death from the first day of starting RRT by age group, which falls sharply during the first 4-5 months, particularly for older patients ( $\geqslant 65$ years).
A 10 year increase in patient age was associated with a 1.68 times increased risk of death within 90 days and a 1.65 times increased risk of death within one year after 90 days (table 5.6).

\section{Survival by gender}

There were no survival differences between genders in an incident cohort of patients starting RRT from 2001 to 2010 and followed up for a minimum of three years until 2013 (figure 5.7). Gender differences were investigated in the first 90 days and one year after the first 90 days and

Table 5.6. Increase in proportional hazard of death for each 10 year increase in age, 2012 incident cohort

\begin{tabular}{lcc}
\hline Interval & $\begin{array}{c}\text { Hazard of death for } \\
\text { 10 year age increase }\end{array}$ & 95\% CI \\
\hline First 90 days & 1.68 & $1.54-1.82$ \\
1 year after first 90 days & 1.65 & $1.56-1.75$ \\
\hline
\end{tabular}

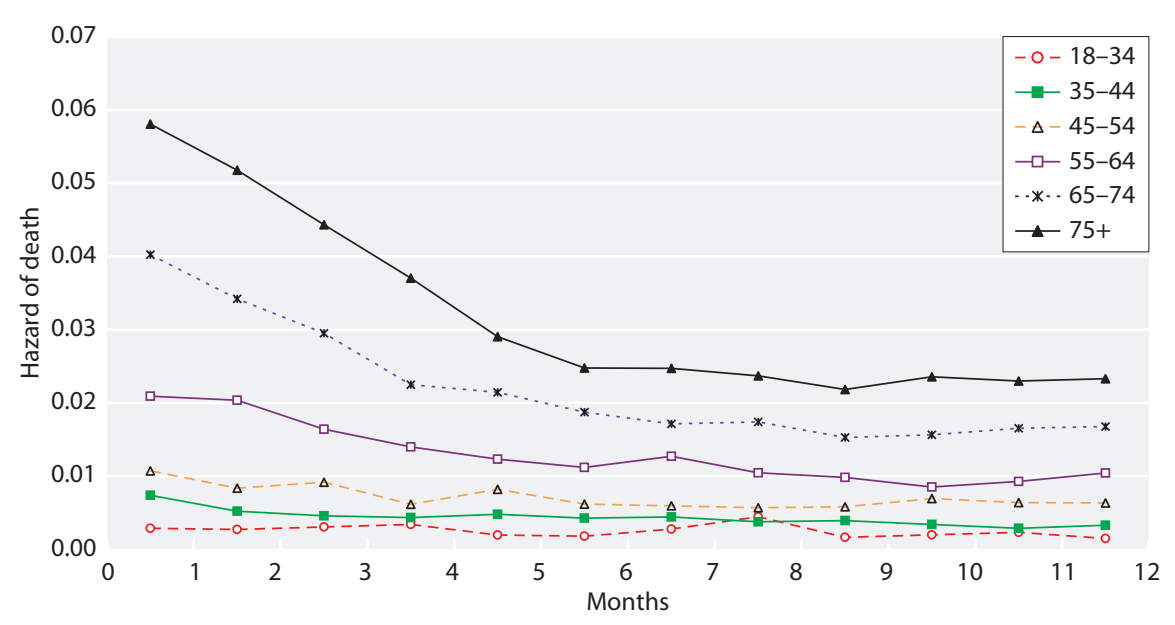

Fig. 5.6. First year monthly hazard of death, by age group 1997-2012 combined incident cohort 


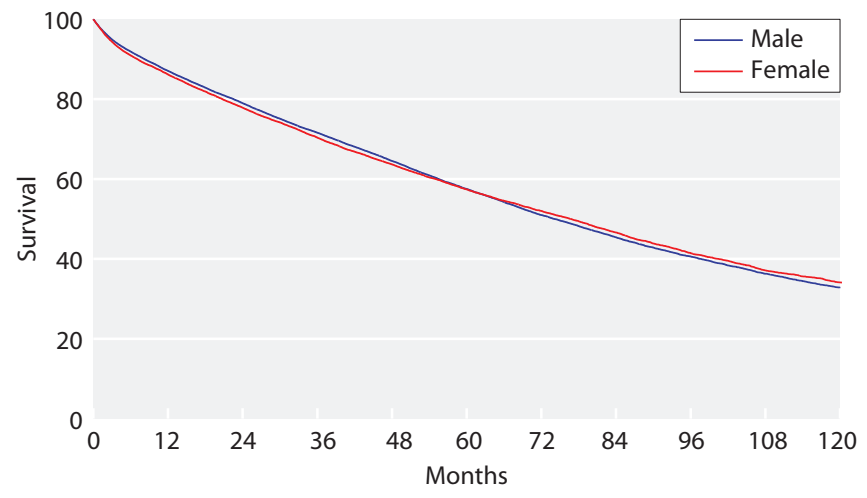

Fig. 5.7. Long term survival of incident patients by gender, 2001-2010 combined cohort, adjusted to age 60

there was also no evidence of a survival difference (data not shown).

\section{Survival in the 2003-2012 cohort}

The death rate per 1,000 patient years in the first year of starting RRT from 2003 to 2012 is shown in figure 5.8. There was a declining trend in the overall death rate with a steeper rate of decline in the older age group $(\geqslant 65$ years). It is important to note that these death rates are not directly comparable with those produced by the United States Renal Data System (USRDS) Registry, as the UK data include the first 90 day period when death rates are higher than subsequent time periods.

The time trend changes are shown in figure 5.9. The left hand plot, which includes only those centres that have been sending data continuously since 2003, shows a similar improvement in survival to the plot in which data from all renal centres are analysed.

One year after 90 days incident patient survival in the 2003-2012 cohort by centre, UK country and overall, can be found in appendix 1, table 5.24.

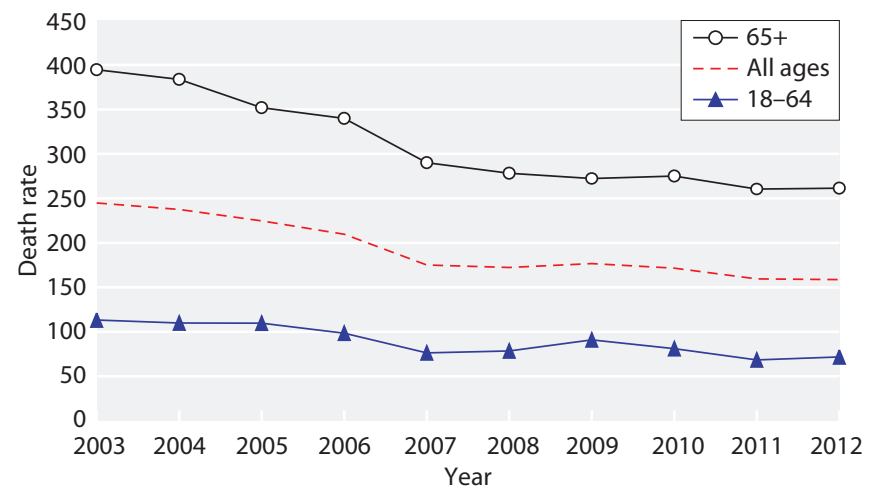

Fig. 5.8. One year incident death rate per 1,000 patient years by age group, 2003-2012 cohort

\section{Long term survival: trends up to 10 years post RRT} start

Longer term survival of patients on RRT continued to improve (tables 5.7 and 5.8). There is a steep decline in survival with advancing age. The unadjusted survival analyses (figures 5.10, 5.11) show a large improvement in one to 10 year survival across the years for both those aged under and those 65 years and over. One year survival amongst patients aged $<65$ years at start of RRT has improved from $87.6 \%$ in the 1998 cohort to $93.1 \%$ in the 2012 cohort.

Similarly, for patients aged $\geqslant 65$ years there has been a $14.8 \%$ absolute improvement in one year survival from the 1998 to 2012 cohorts (table 5.8). As these are observational data it remains difficult to attribute this reduction in risk of death to any specific improvements in care.

\section{Change in survival on RRT by vintage}

Figure 5.12 shows the instantaneous hazard of death by age group. There is little evidence of a worsening prognosis with time on RRT (vintage) for the majority

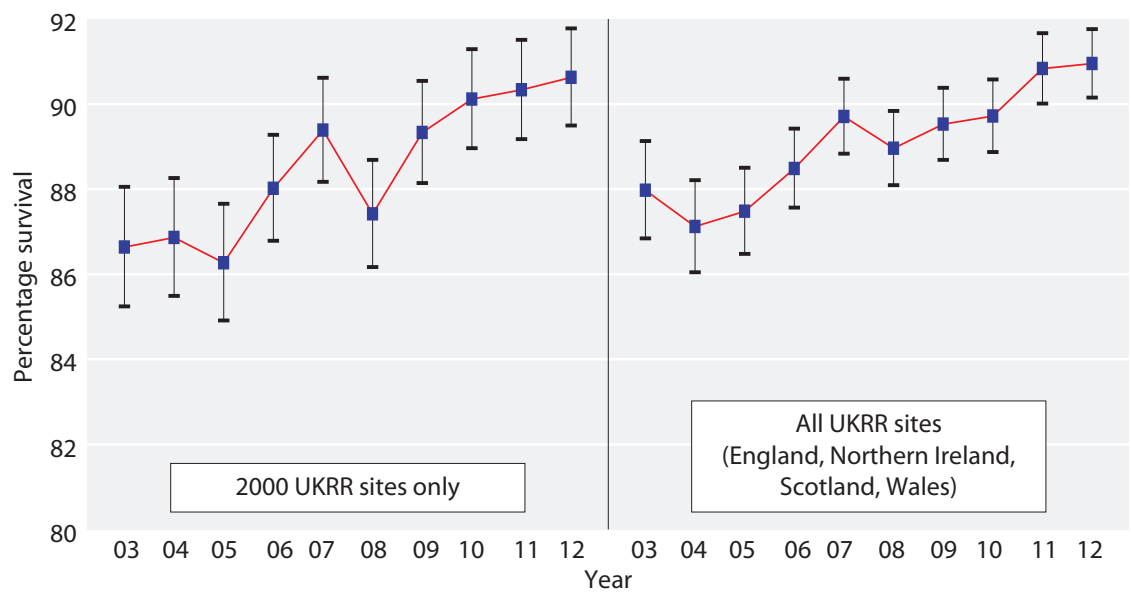

Fig. 5.9. Change in one year after 90 day survival, 2003-2012 incident cohort (adjusted to age 60)

Showing 95\% confidence intervals 
Table 5.7. Unadjusted survival of incident patients, 1998-2012 cohort for patients aged 18-64 years

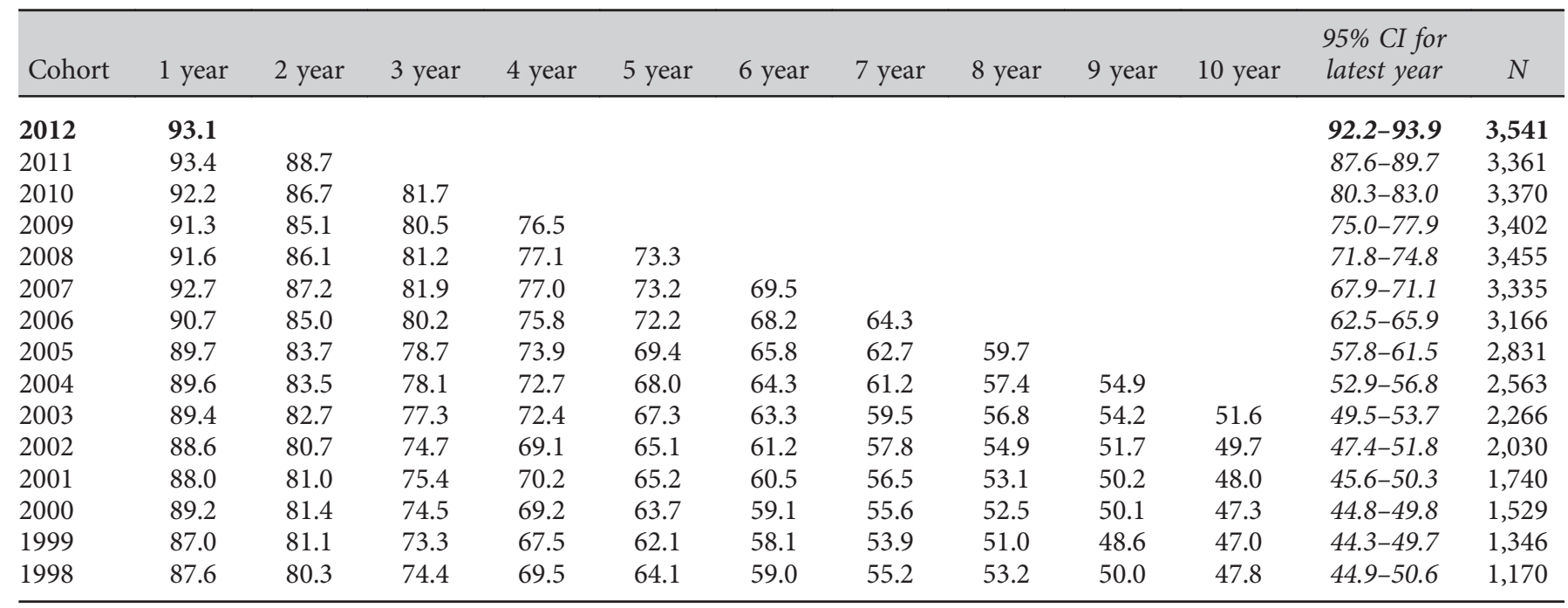

Table 5.8. Unadjusted survival of incident patients, $1998-2012$ cohort for patients aged $\geqslant 65$ years

\begin{tabular}{|c|c|c|c|c|c|c|c|c|c|c|c|c|}
\hline Cohort & 1 year & 2 year & 3 year & 4 year & 5 year & 6 year & 7 year & 8 year & 9 year & 10 year & $\begin{array}{l}95 \% \text { CI for } \\
\text { latest year }\end{array}$ & $N$ \\
\hline 2012 & 77.4 & & & & & & & & & & $75.9-78.8$ & 3,340 \\
\hline 2010 & 76.4 & 63.5 & 51.3 & & & & & & & & $49.6-53.0$ & 3,280 \\
\hline 2009 & 76.6 & 63.4 & 52.6 & 41.7 & & & & & & & $40.0-43.4$ & 3,375 \\
\hline 2008 & 74.7 & 61.4 & 50.2 & 40.7 & 32.6 & & & & & & $30.9-34.2$ & 3,185 \\
\hline 2005 & 71.1 & 57.3 & 45.4 & 36.3 & 28.0 & 21.3 & 16.8 & 12.7 & & & $11.5-14.0$ & 2,939 \\
\hline 2004 & 69.2 & 54.3 & 42.8 & 34.3 & 27.1 & 21.4 & 16.7 & 13.3 & 10.3 & & $9.2-11.5$ & 2,626 \\
\hline 2003 & 68.4 & 53.8 & 42.0 & 32.2 & 24.7 & 18.5 & 14.6 & 11.4 & 8.9 & 7.2 & $6.2-8.3$ & 2,315 \\
\hline 2002 & 66.0 & 50.7 & 40.3 & 31.8 & 23.9 & 18.3 & 13.7 & 10.9 & 8.3 & 6.5 & $5.5-7.7$ & 2,086 \\
\hline 2001 & 66.5 & 51.8 & 38.4 & 28.9 & 21.9 & 16.2 & 12.2 & 9.3 & 7.4 & 5.7 & $4.6-6.9$ & 1,710 \\
\hline
\end{tabular}

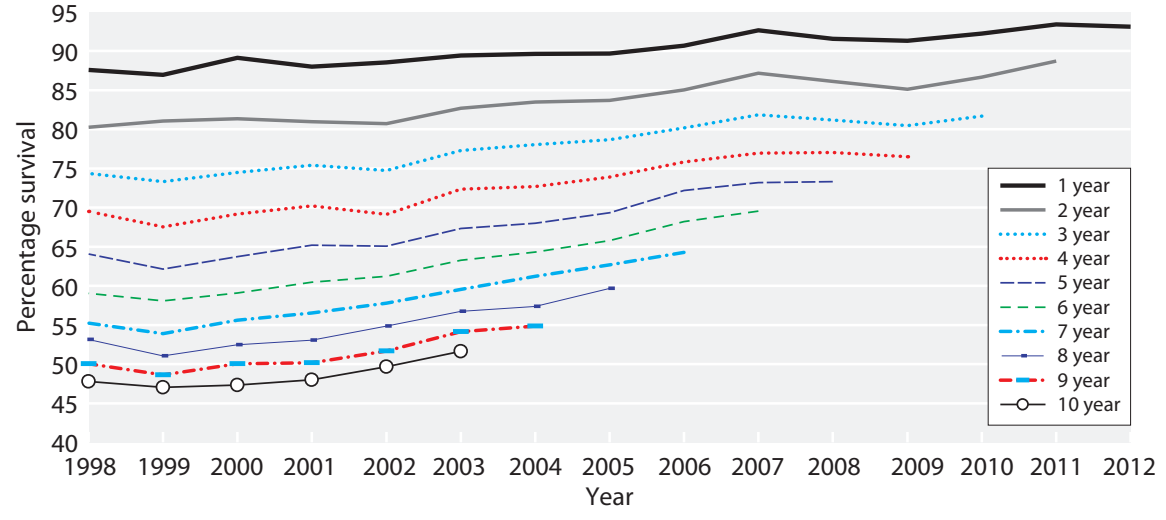

Survival in UK RRT patients in 2013
Fig. 5.10. Change in long term survival by year of starting RRT, for incident patients aged 18-64 years 

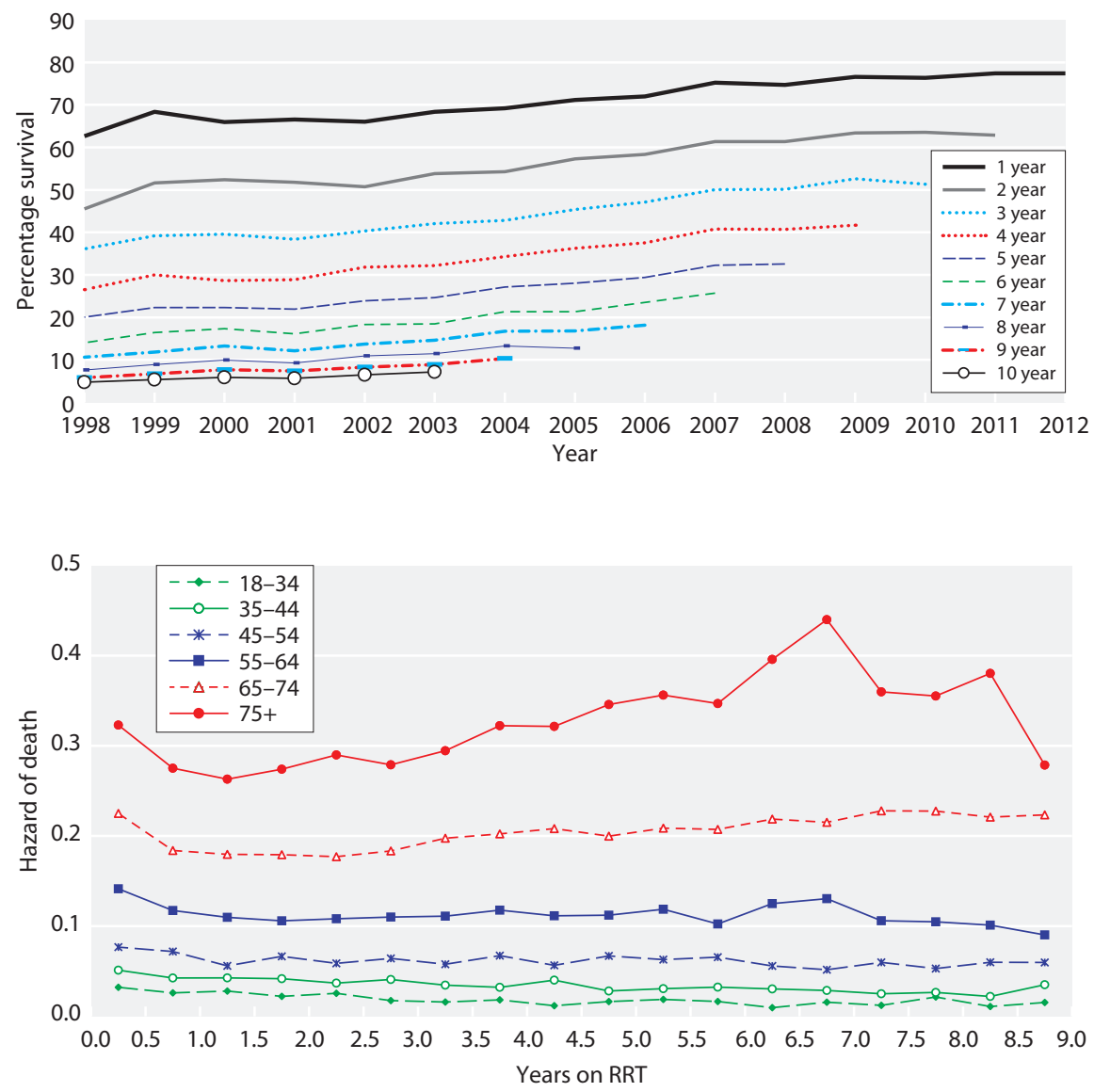

Fig. 5.11. Change in long term survival by year of starting RRT, for incident patients aged $\geqslant 65$ years
Fig. 5.12. Six monthly hazard of death, by vintage and age group, 1997-2012 incident cohort after day 90 (not censored at transplantation) of incident RRT patients in the UK (not censored for transplantation), although an increased hazard over time is evident for incident patients aged 75 years and older. The apparent vintage effect when censoring for transplantation (data not shown) is at least in part because these younger and healthier patients are only included in the survival calculation up to the date of transplantation. In the older age groups there were decreasing numbers remaining alive beyond seven years accounting for the increased variability seen. Figures 5.13 and 5.14 show these data for the non-diabetic and diabetic patients respectively.

Centre variability in one year after 90 days survival In the analysis of the 2012 incident cohort survival data, some of the smaller centres had wide confidence

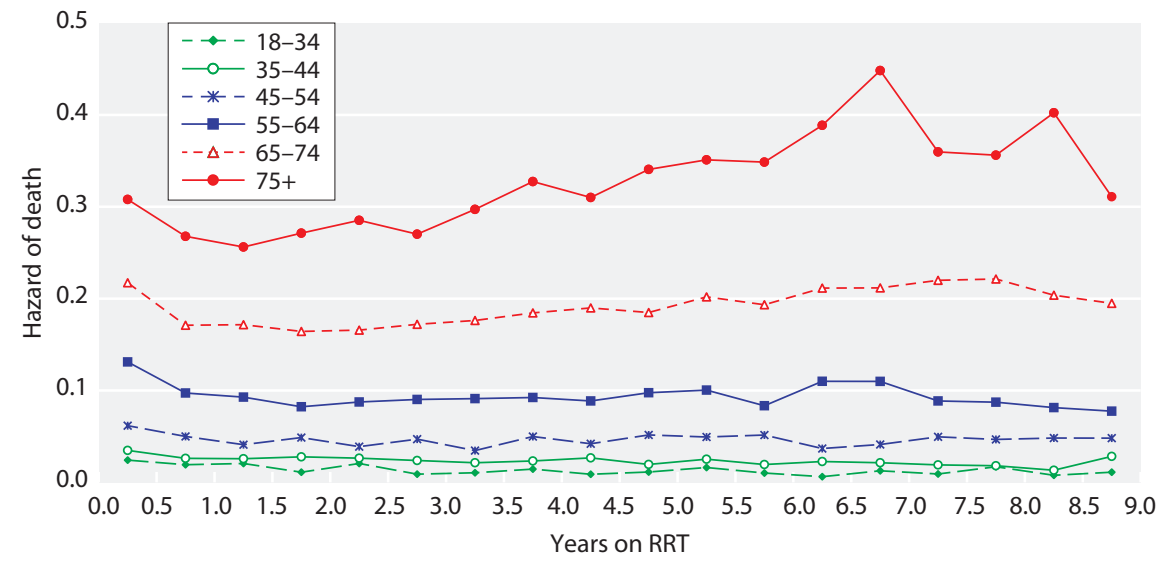

Fig. 5.13. Six monthly hazard of death, by vintage and age group, 1997-2012 non-diabetic incident cohort after day 90 (not censored at transplantation) 


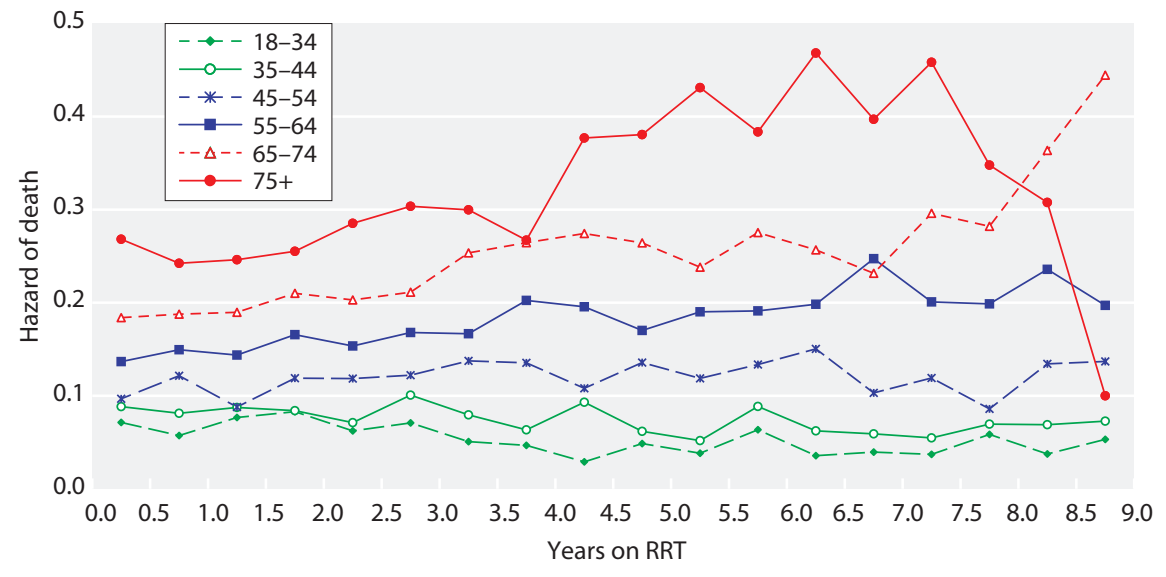

Fig. 5.14. Six monthly hazard of death, by vintage and age group, 1997-2012 diabetic incident cohort after day 90 (not censored at transplantation) intervals (appendix 1, table 5.22) due to small numbers of patients. This was addressed by including a larger cohort across several years, which will also assess sustained performance. Similar to previous years, this is shown as a rolling four year cohort from 2009 to 2012. These data are presented as a funnel plot in figure 5.15. Table 5.9 allows centres to be identified on this graph by finding the number of patients treated by the centre and then looking up this number on the $\mathrm{x}$-axis. One centre (Swansea) had survival below the 95\% lower limit whilst four centres (London St. George's, London Guy's, Stevenage, Western Trust Northern Ireland) had survival above the $95 \%$ upper limit.

With 71 centres it would be expected that only three centres would be outside these limits by chance. It is important to acknowledge that these data have not been adjusted for any patient related factor except age (i.e. not comorbidity, primary renal disease or ethnicity) and have not been censored at transplantation, so the effect of differing centre rates of transplantation was not taken into account. Figure 5.16 illustrates the effect of adjusting for comorbidity on survival in centres with good comorbidity returns $(\geqslant 85 \%)$, with the biggest improvement in survival seen in Swansea. Adjustment for comorbidity could have an important effect on survival results for in some renal centres like Swansea that appear to have a higher comorbid burden in their RRT population. This could affect the outlier status of centres as illustrated in figure 5.15, but due to poor comorbidity returns for many renal centres, comorbidity adjustment for the entire incident RRT population is not yet possible. Case mix adjustment performed in a cohort of incident patients starting RRT in England from 2002 to 2006 and linked to the Hospital Episodes Statistics (HES) data, found that three of the four survival outliers were

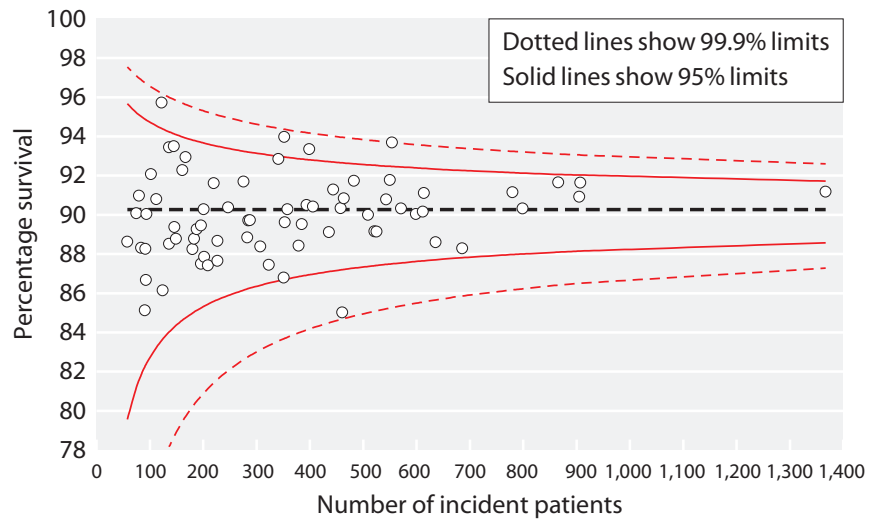

Fig. 5.15. Funnel plot for age adjusted one year after 90 days survival, 2009-2012 incident cohort

no longer outliers after adjustment for HES-derived case mix [10]. Swansea could not be evaluated in this analysis as this was only for England, but the study results highlight that variability in survival between centres is affected by case mix.

Also see appendix 1, table 5.22 and 5.23 for unadjusted and adjusted survival together with 95\% confidence intervals for incident patient survival one year after 90 days and at 90 days. The one year after 90 days survival for the 2003 to 2012 cohort can be found in appendix 1, table 5.24.

Centre variability in one year after 90 day survival: impact of adjustment for comorbidity

Although comorbidity returns to the UKRR have remained poor, there was an increase in the number of centres returning $\geqslant 85 \%$ of comorbidity data to the UKRR for patients starting RRT in 2012. Using the combined incident cohort from 2009-2012, 24 centres had returned comorbidity data for $\geqslant 85 \%$ of patients and 
Table 5.9. Age adjusted (to age 60) one year after 90 day survival, 2009-2012 incident cohort

\begin{tabular}{|c|c|c|c|c|c|c|c|c|c|}
\hline \multirow[b]{2}{*}{ Centre } & \multirow[b]{2}{*}{$N$} & \multirow{2}{*}{$\begin{array}{l}\text { Age adjusted } \\
\text { survival } \\
\%\end{array}$} & \multicolumn{2}{|c|}{ Limits for funnel plot } & \multirow[b]{2}{*}{ Centre } & \multirow[b]{2}{*}{$N$} & \multirow{2}{*}{$\begin{array}{l}\text { Age adjusted } \\
\text { survival } \\
\%\end{array}$} & \multicolumn{2}{|c|}{ Limits for funnel plot } \\
\hline & & & $\begin{array}{c}\text { Lower } \\
95 \% \text { limit }\end{array}$ & $\begin{array}{c}\text { Upper } \\
\text { 95\% limit }\end{array}$ & & & & $\begin{array}{c}\text { Lower } \\
95 \% \text { limit }\end{array}$ & $\begin{array}{c}\text { Upper } \\
95 \% \text { limit }\end{array}$ \\
\hline Clwyd & 80 & 91.0 & 81.6 & 95.1 & Newc & 351 & 86.8 & 86.7 & 92.9 \\
\hline Ulster & 84 & 88.3 & 81.8 & 95.0 & L St.G & 352 & 94.0 & 86.7 & 92.9 \\
\hline Carlis & 91 & 85.1 & 82.2 & 94.9 & Stoke & 353 & 89.6 & 86.7 & 92.9 \\
\hline Newry & 92 & 88.3 & 82.3 & 94.9 & Hull & 358 & 90.3 & 86.7 & 92.9 \\
\hline Wrexm & 93 & 86.7 & 82.4 & 94.8 & Middlbr & 379 & 88.4 & 86.8 & 92.9 \\
\hline Bangor & 94 & 90.0 & 82.4 & 94.8 & B Heart & 385 & 89.5 & 86.9 & 92.8 \\
\hline Klmarnk & 136 & 88.5 & 84.0 & 94.2 & Nottm & 444 & 91.3 & 87.1 & 92.7 \\
\hline Krkcldy & 136 & 93.4 & 84.0 & 94.2 & Swanse & 455 & 84.3 & 87.2 & 92.7 \\
\hline Ipswi & 145 & 93.5 & 84.2 & 94.1 & Camb & 458 & 90.3 & 87.2 & 92.7 \\
\hline Donc & 146 & 89.4 & 84.3 & 94.1 & Kent & 464 & 90.8 & 87.2 & 92.6 \\
\hline Basldn & 149 & 88.8 & 84.3 & 94.1 & Exeter & 483 & 91.7 & 87.3 & 92.6 \\
\hline York & 161 & 92.3 & 84.6 & 94.0 & Prestn & 509 & 90.0 & 87.4 & 92.5 \\
\hline Truro & 167 & 92.9 & 84.7 & 93.9 & Salford & 521 & 89.2 & 87.4 & 92.5 \\
\hline Chelms & 180 & 88.2 & 85.0 & 93.8 & L Kings & 525 & 89.1 & 87.4 & 92.5 \\
\hline Dudley & 183 & 88.8 & 85.0 & 93.8 & Leeds & 543 & 90.8 & 87.5 & 92.5 \\
\hline Liv Ain & 188 & 89.3 & 85.1 & 93.7 & Sheff & 550 & 91.8 & 87.5 & 92.5 \\
\hline Airdrie & 196 & 87.5 & 85.2 & 93.7 & L Guys & 554 & 93.7 & 87.5 & 92.5 \\
\hline Abrdn & 196 & 89.4 & 85.2 & 93.7 & Bristol & 571 & 90.3 & 87.5 & 92.4 \\
\hline Derby & 283 & 88.8 & 86.2 & 93.2 & Leic & 905 & 90.9 & 88.1 & 92.0 \\
\hline Norwch & 285 & 89.7 & 86.2 & 93.2 & L Barts & 907 & 91.6 & 88.1 & 92.0 \\
\hline Dorset & 288 & 89.7 & 86.3 & 93.2 & L West & 1,367 & 91.2 & 88.6 & 91.7 \\
\hline Edinb & 307 & 88.4 & 86.4 & 93.1 & & & & & \\
\hline
\end{tabular}

these centres were included in this analysis. Adjustment was first performed to age 60 , then to the average distribution of primary renal diagnoses for the 24 centres. Further adjustment was then made to the average distribution of comorbidities present at those centres (table 5.10).

It can be seen that adjustment for age has the largest effect, most notably in those centres with the lower unadjusted survival figures. Survival improved for all centres after adjustment for age, as the average age for incident patients was higher than the adjustment to the average age of 60 years. There were only minor differences for most centres after adjustment for primary renal diagnosis (PRD), but survival increased by $\geqslant 1 \%$ for four centres (Swansea, Wrexham, Newry, Derby). In six centres (Swansea, Newry, Basildon, Middlesbrough, Bradford, Leeds) adjustment for comorbidity had a noticeable effect on adjusted survival (table 5.10, figure 5.16) helping explain the lower survival noted in figure 5.15. After adjustment for age, PRD and comorbidity, Swansea and Ulster had a noticeable improvement in survival of $10.3 \%$ and $7.5 \%$ respectively. 


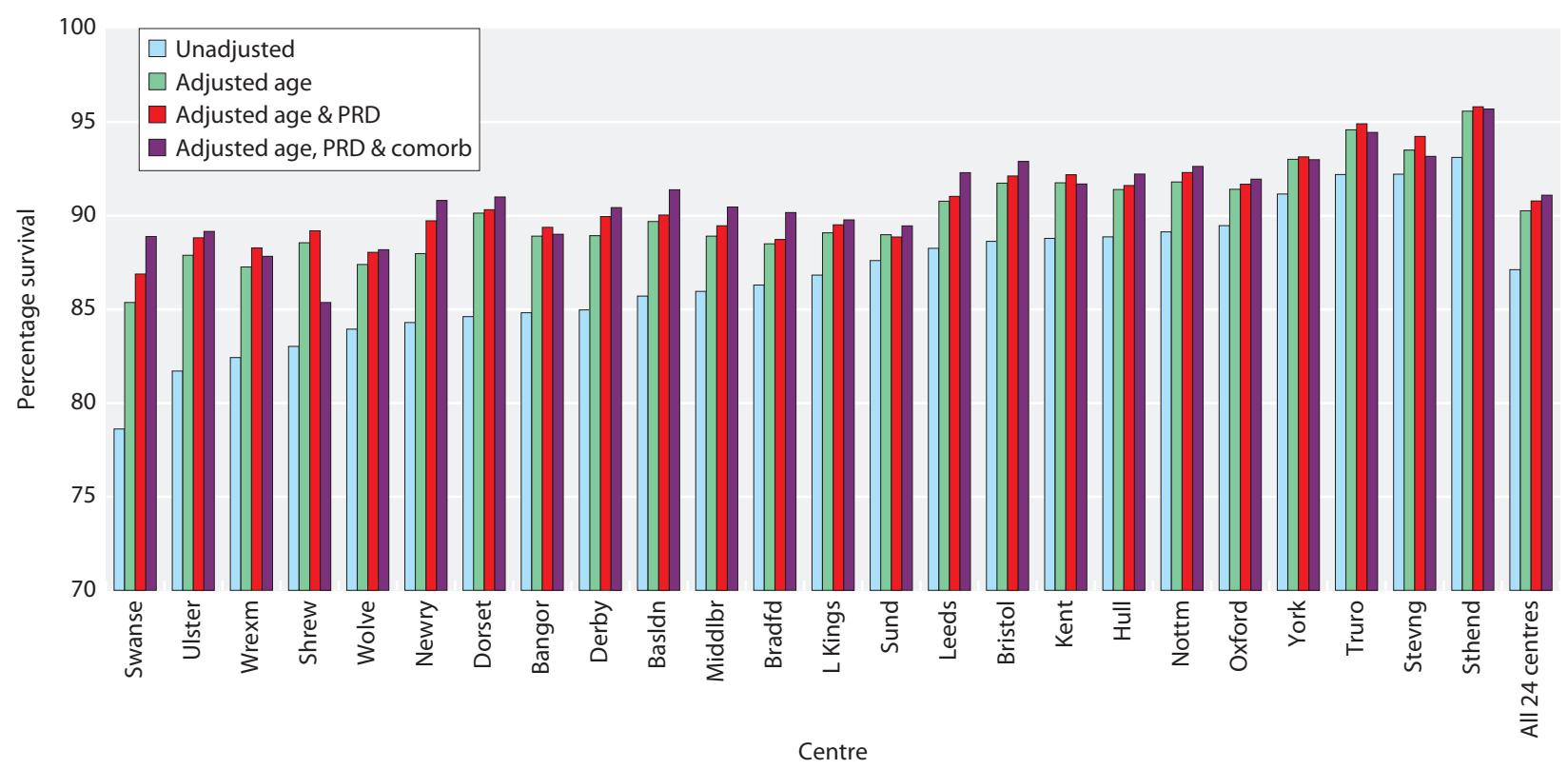

Fig. 5.16. The effect on survival after sequential adjustment for age, PRD and comorbidity, 2009-2012 incident cohort

Table 5.10. The effect of adjustment for age, $\mathrm{PRD}$ and comorbidity on survival, $2009-2012$ incident cohort, $\%$ survival one year after 90 days

\begin{tabular}{|c|c|c|c|c|}
\hline Centre* & Unadjusted & Age adjusted & Age, PRD adjusted & $\begin{array}{l}\text { Age, } \mathrm{PRD} \text { and } \\
\text { comorbidity adjusted }\end{array}$ \\
\hline Swanse & 78.6 & 85.4 & 86.9 & 88.9 \\
\hline Wrexm & 82.4 & 87.3 & 88.3 & 87.8 \\
\hline Shrew & 83.0 & 88.6 & 89.2 & 85.4 \\
\hline Wolve & 83.9 & 87.4 & 88.1 & 88.2 \\
\hline Bangor & 84.8 & 88.9 & 89.4 & 89.0 \\
\hline Derby & 85.0 & 88.9 & 90.0 & 90.4 \\
\hline Basldn & 85.7 & 89.7 & 90.0 & 91.4 \\
\hline Middlbr & 86.0 & 88.9 & 89.5 & 90.5 \\
\hline Bradfd & 86.3 & 88.5 & 88.7 & 90.2 \\
\hline L Kings & 86.8 & 89.1 & 89.5 & 89.8 \\
\hline Hull & 88.9 & 91.4 & 91.6 & 92.2 \\
\hline Nottm & 89.1 & 91.8 & 92.3 & 92.6 \\
\hline Oxford & 89.5 & 91.4 & 91.7 & 92.0 \\
\hline York & 91.2 & 93.0 & 93.1 & 93.0 \\
\hline Truro & 92.2 & 94.6 & 94.9 & 94.5 \\
\hline Stevng & 92.2 & 93.5 & 94.2 & 93.2 \\
\hline Sthend & 93.1 & 95.6 & 95.8 & 95.7 \\
\hline All 24 centres & 87.1 & 90.3 & 90.8 & 91.1 \\
\hline
\end{tabular}

${ }^{*}$ Centre included if $\geqslant 85 \%$ comorbidity data available 


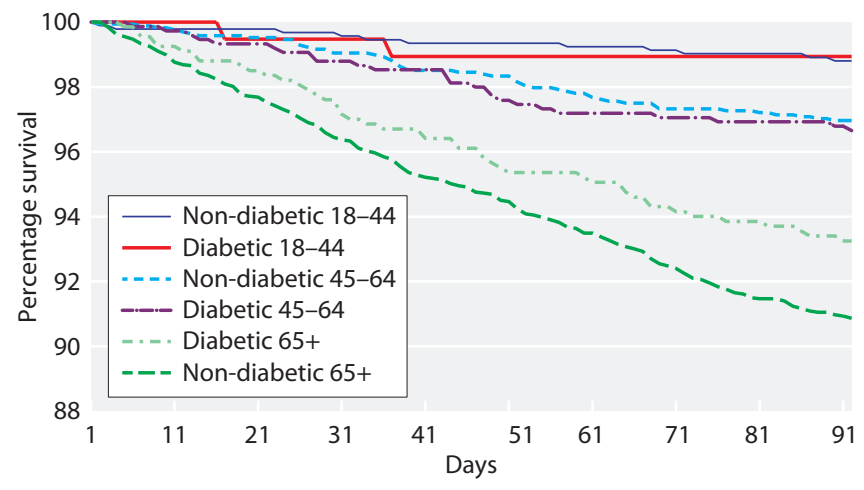

Fig. 5.17. Survival at 90 days for incident diabetic and nondiabetic patients by age group for patients starting RRT, 2012 cohort

\section{Survival in patients with diabetes}

Although it has previously been shown that diabetic patients have worse long term survival compared to non-diabetic patients [3], non-diabetic patient survival in the older age group ( $\geqslant 65$ years) was worse compared to diabetic patients in the same age group during the first 90 days of starting RRT (2012 cohort) (figure 5.17) and in the subsequent year (figure 5.18); this might be due to patient selection.

Long term survival for diabetic and non-diabetic patients was evaluated in a cohort of patients starting RRT from 2001 to 2010 with a minimum of three years follow up until 2013. These data show large differences between diabetic and non-diabetic patient survival in the age groups 18-44 and 45-64 years, but there was very little difference in five year survival between diabetic and non-diabetic patients in the older age group $(\geqslant 65$ years). In age group $18-44,89 \%$ of non-diabetic patients were alive five years after start of RRT compared to $71 \%$

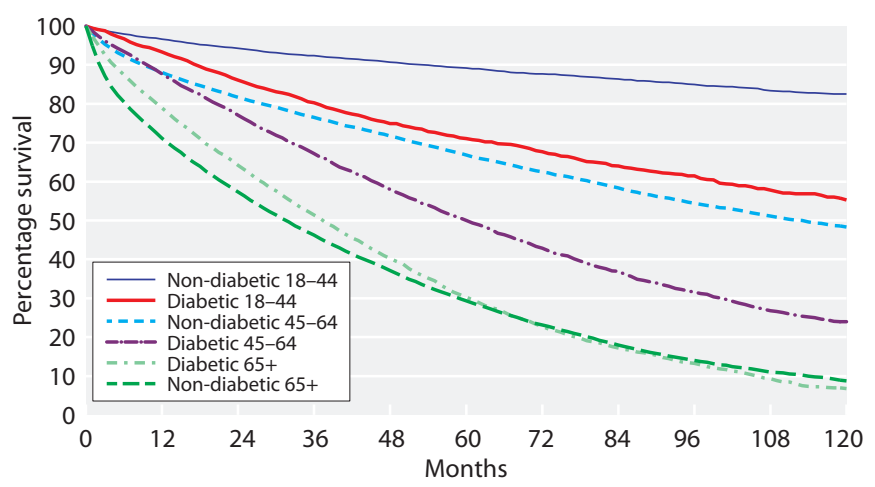

Fig. 5.19. Long term survival for incident diabetic and nondiabetic patients by age group, 2001-2010 cohort, followed up for a minimum of three years

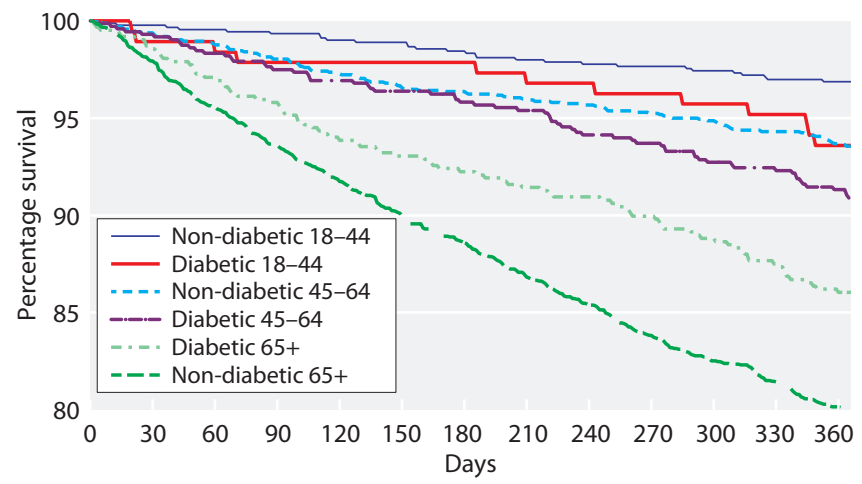

Fig. 5.18. Survival at one year after 90 days for incident diabetic and non-diabetic patients by age group for patients starting RRT, 2012 cohort

for diabetic patients. In the age group $45-64,67 \%$ of nondiabetic patients were alive five years after start of RRT compared to $50 \%$ for diabetic patients (figure 5.19).

\section{Median life expectancy on RRT}

Figure 5.20 shows median life expectancy for incident RRT and diabetic patients after 90 days by age group. Incident patients starting RRT from 2001 to 2010 have been included in this analysis and patients were followed up for a minimum of three years. The estimated median survival will be different for low risk patients (e.g. polycystic kidney disease with a transplant) vs. high risk patients (diabetes with previous myocardial infarction on dialysis) even within the same age group. Median life years remaining for non-diabetic patients were also

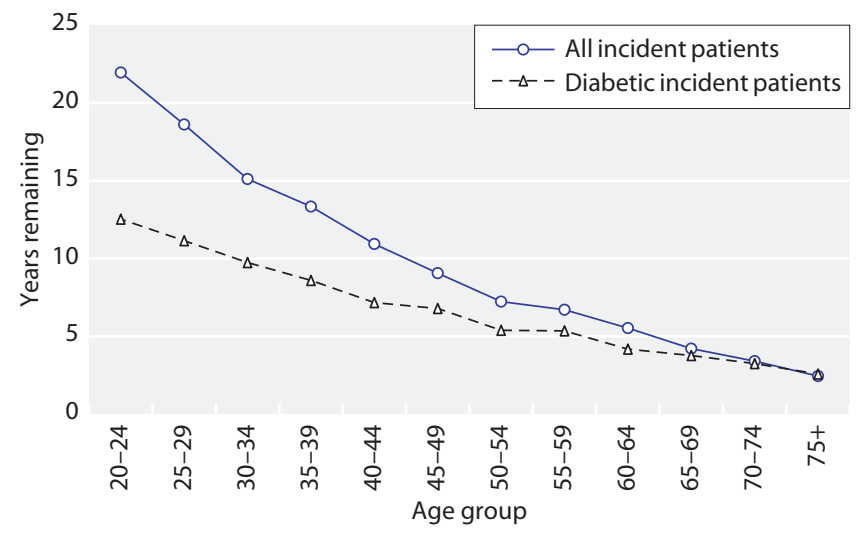

Fig. 5.20. Median life expectancy on RRT after 90 days, by age group, incident and incident diabetic patients starting RRT from 2001-2010 
Table 5.11. One year survival of prevalent RRT patients in the UK (unadjusted unless indicated otherwise)

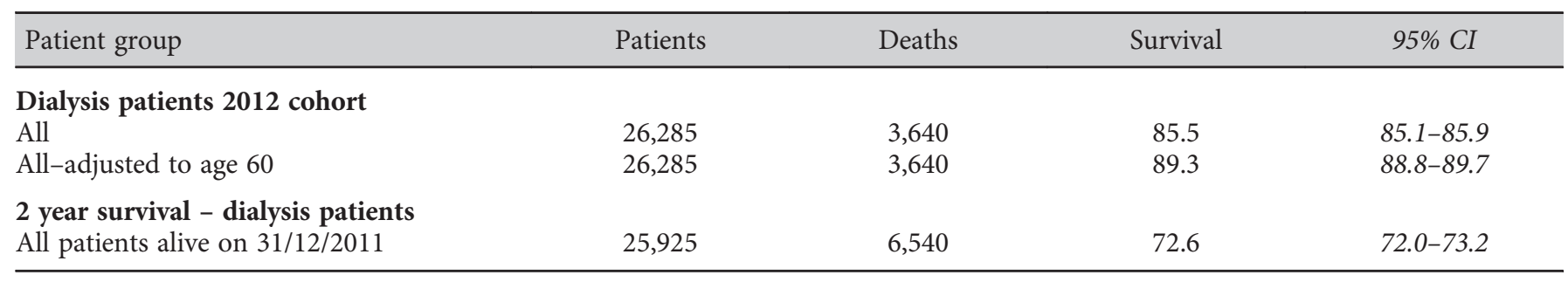

Cohorts of patients alive on $31 / 12 / 2012$ unless indicated otherwise

calculated and show that median life expectancy for patients younger than 45 was on average nine years more for non-diabetic patients (data not shown) compared with age matched diabetic patients. In the older age group ( $\geqslant 65$ years), the median life years remaining were similar between diabetic and non-diabetic patients.

\section{Survival in prevalent dialysis patients}

\section{Overall survival}

Table 5.11 shows the one year survival for prevalent patients on dialysis. One year age adjusted survival for prevalent dialysis patients remained relatively unchanged at $89.3 \%$ in the 2012 cohort compared to $89.7 \%$ in the 2011 cohort.

\section{Survival by UK country}

The one year death rate for prevalent dialysis patients in each UK country is shown in table 5.12 for the 2012 cohort. There was evidence that the one year death rate in Wales was higher than in England and Northern Ireland; the higher median age in Wales compared to England and socio-economic reasons like life expectancy of the population and area deprivation, would affect the death rate in Wales. These results are unadjusted for age, PRD or comorbidity.

Table 5.12. One year death rate per 1,000 prevalent dialysis patient years in the 2012 cohort and median age of prevalent patients by country

\begin{tabular}{lcccc}
\hline & England & N Ireland & Scotland & Wales \\
\hline Death rate & 154 & 145 & 168 & 198 \\
$95 \%$ CI & $149-160$ & $119-160$ & $150-188$ & $172-226$ \\
Median age & 66.2 & 68.4 & 66.2 & 68.2 \\
\hline
\end{tabular}

Survival in UK RRT patients in 2013

\section{One year survival of prevalent dialysis patients by centre}

The age adjusted (adjusted to age 60) one year survival of dialysis patients by centre is illustrated in a funnel plot (figure 5.21). With over 70 centres included, it would be expected by chance that three centres would fall outside the $95 \%$ ( 1 in 20 ) confidence limits. The survival for four centres (Doncaster, Shrewsbury, Newcastle, Manchester RI) was below the 95\% confidence limits, and for three centres (Cambridge, Birmingham QEH, Sheffield) above the 95\% confidence limits.

Case mix adjustment performed in a cohort of incident patients starting RRT in England from 2002 to 2006 and linked to the HES data, showed that the lower than expected survival in Newcastle may be explained by case mix [10]. This study found that three of the four survival outliers were no longer outliers after adjustment for HES-derived case mix. It is not yet possible to routinely perform this adjustment using HES-linked data, but looking back at the 2002-2006 HES-linked data, Newcastle's survival did increase more than other centres after case mix adjustment and so their current

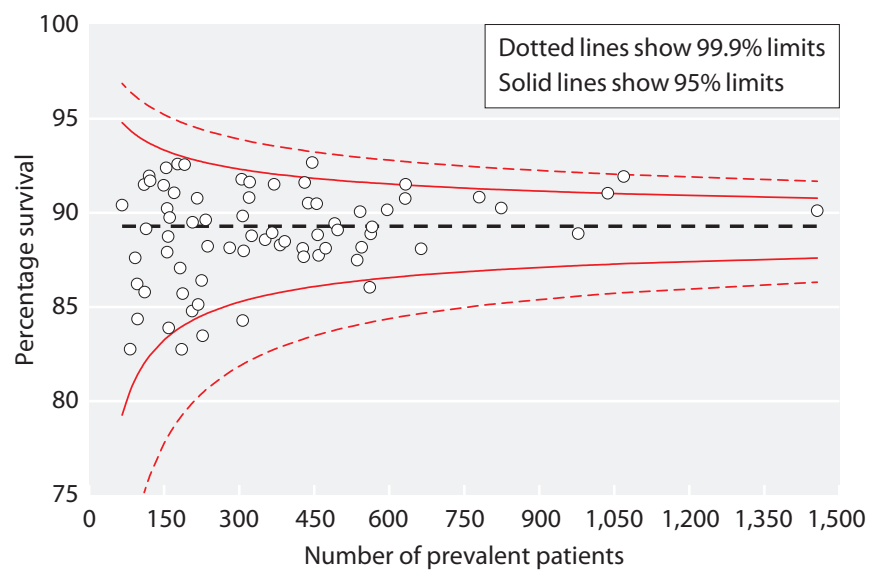

Fig. 5.21. One year survival funnel plot of prevalent dialysis patients by centre adjusted to age 60, 2012 cohort

Nephron 2015;129(suppl1):99-129 
Table 5.13. One year survival of prevalent dialysis patients in each centre (adjusted to age 60), 2012 cohort

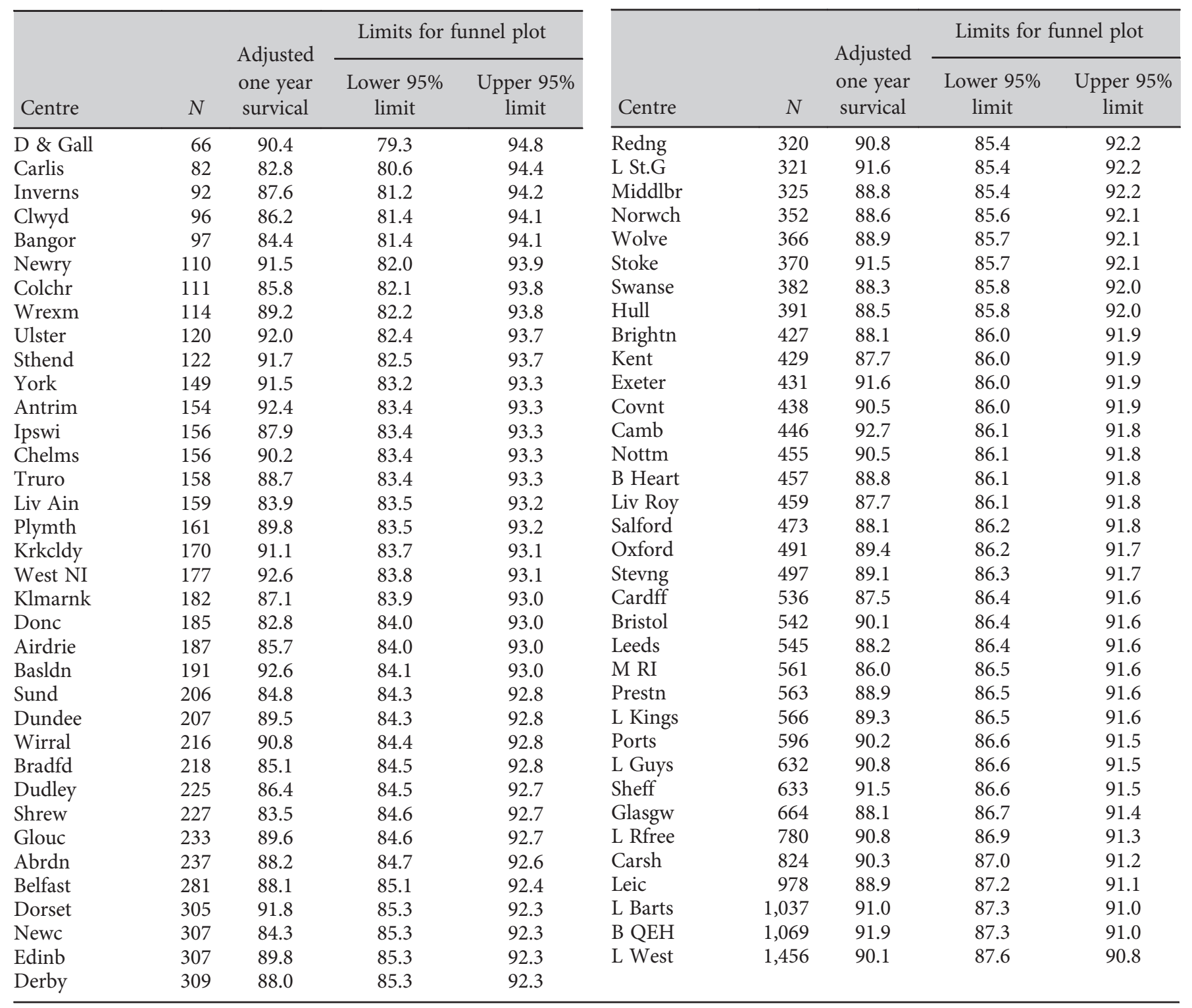

outlier status may reflect a higher comorbid burden in their dialysis population. Considering other outliers this year, Shrewsbury's survival did not increase more than the average after the HES-derived case mix adjustment and the impact from case mix cannot be commented on for Doncaster and Manchester RI as they were not part of the 2002-2006 HES-linked cohort analysis due to joining the UKRR only in 2007.

The funnel plot analysis shows an increase in the number of centres that are outliers below the below the 95\% lower limits compared to the 2011 cohort when there were two outlying centres. The number of centres that were outliers above the 95\% upper limit increased from two in the 2011 cohort to three in this most recent analysis.

Table 5.13 allows centres in figure 5.21 to be identified by finding the number of patients treated by the centre and the corresponding survival and then looking this up on the axes of the funnel plot.

One year survival of dialysis patients by centre is illustrated in figures 5.22 and 5.23 for patients aged $<65$ years and those aged $\geqslant 65$ years. 


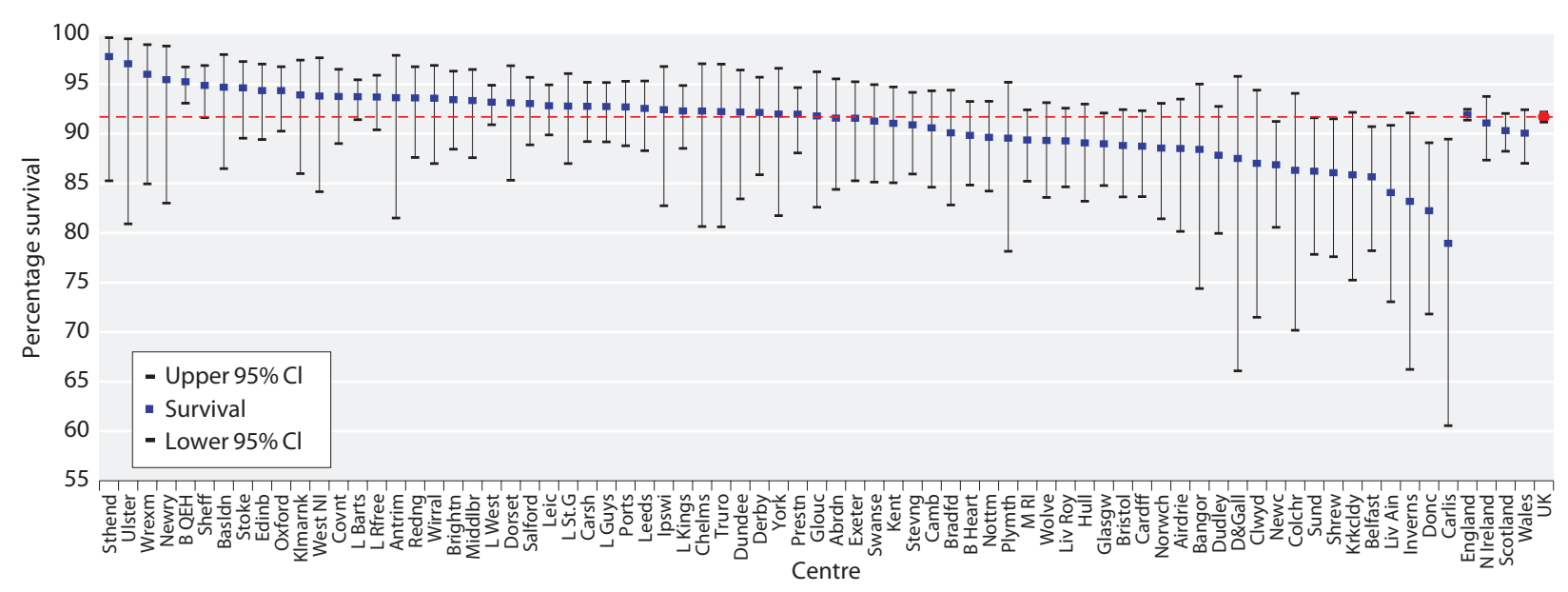

Fig. 5.22. One year survival of prevalent dialysis patients aged under 65 by centre, 2012 cohort

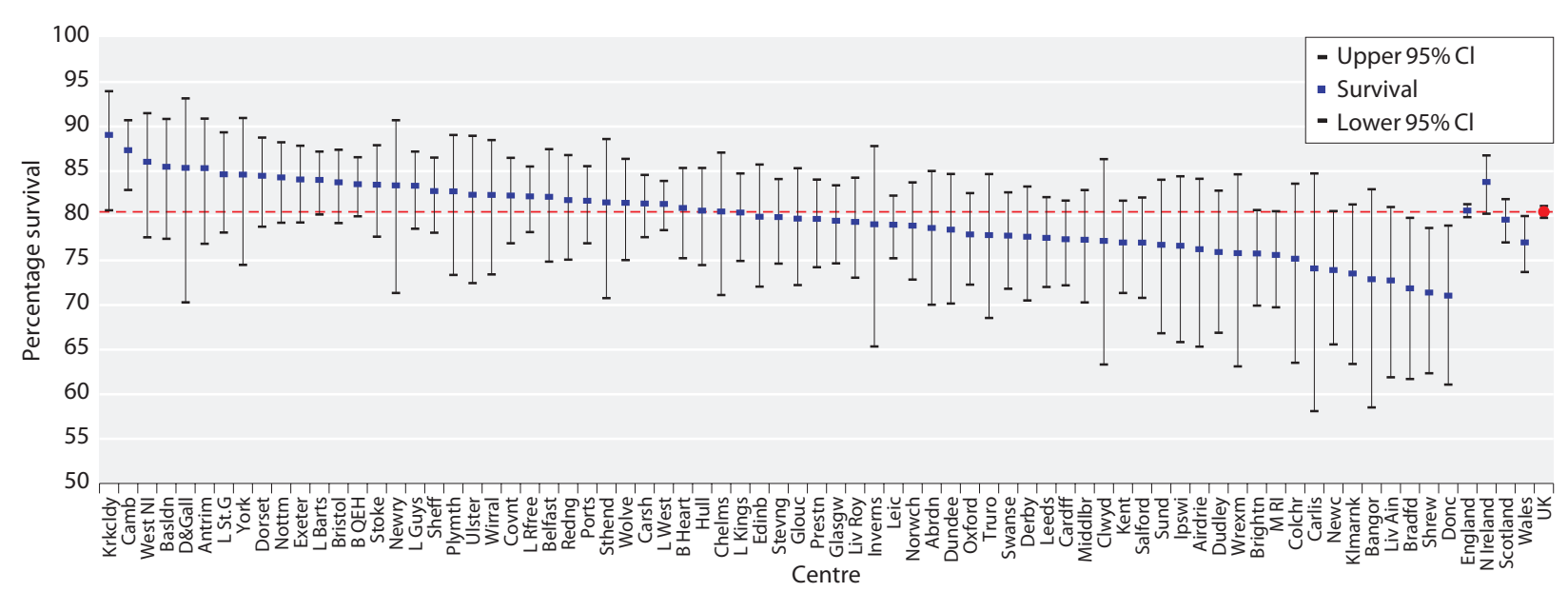

Fig. 5.23. One year survival of prevalent dialysis patients aged 65 years and over by centre, 2012 cohort

Survival by age group

Figure 5.24 shows the one year survival of prevalent dialysis patients who were alive and receiving dialysis on 31st December 2012, stratified by age group. There was a curvilinear decrease in survival with increasing age, especially so for patients aged $\geqslant 75$ years (figure 5.24).

One year death rate in prevalent dialysis patients in the 2012 cohort by age group

The death rates for prevalent patients on dialysis by age group are shown in figure 5.25. The younger patients included in this analysis are a selected higher risk group, as the similar aged transplanted patients have been excluded. The increase in the death rate was not linear with age; with a 10 year increase in age in the younger

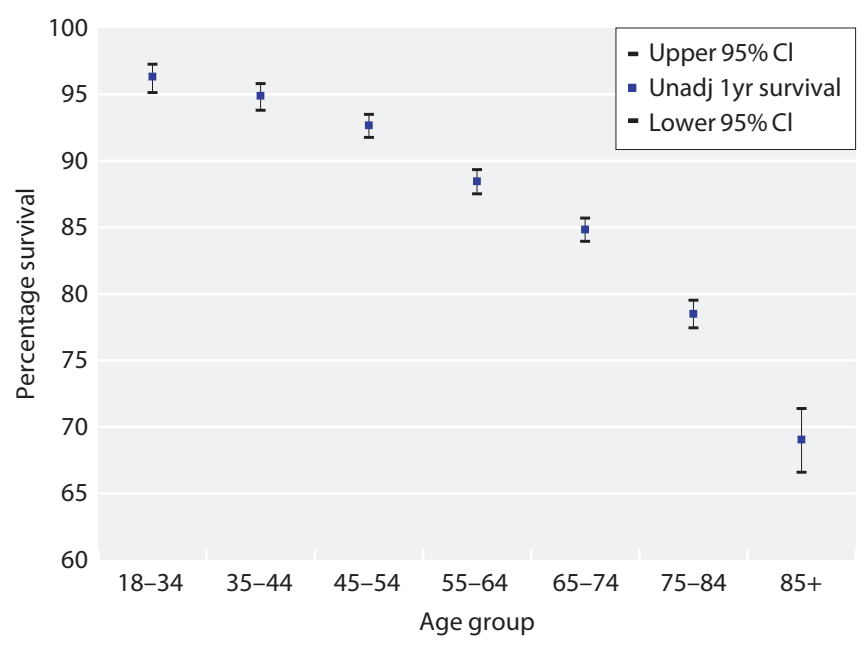

Fig. 5.24. One year survival of prevalent dialysis patients by age group, 2012 cohort 


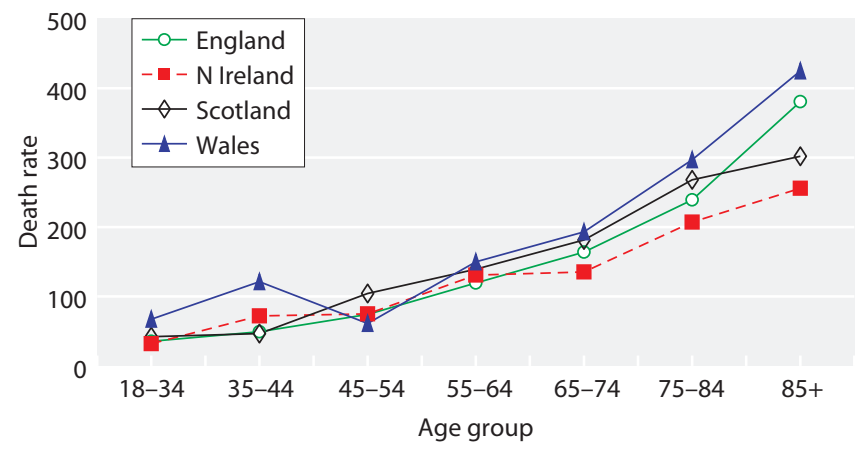

Fig. 5.25. One year death rate per 1,000 patient years by UK country and age group for prevalent dialysis patients, 2012 cohort

patients, the death rate increased by about 15 deaths per 1,000 patient years compared with an increase of about 130 deaths per 1,000 patient years in the older age groups. There was no evidence that the apparent differences between the countries were significant except for Wales where there was evidence that the death rate was higher compared to England.

Time trends in survival, 2003 to 2012

Figure 5.26 illustrates that one year survival for prevalent dialysis patients has gradually improved since 2003 . In Northern Ireland and Wales the numbers of patients were much smaller than in England and survival was therefore more variable with very wide confidence intervals, making it difficult to draw conclusions on trends. The change in prevalent survival by centre over the
Table 5.14. One year survival of prevalent RRT patients in the UK by age group and diabetic status

\begin{tabular}{lrrrr}
\hline Patient group & Patients & Deaths & Survival & 95\% CI \\
\hline Dialysis patients 2012 cohort & & & \\
All, age <65 & 12,273 & 940 & 91.7 & $91.2-92.2$ \\
All, age 65+ & 14,012 & 2,700 & 80.4 & $79.8-81.1$ \\
Non-diabetic <65 & 9,611 & 592 & 93.3 & $92.7-93.8$ \\
Non-diabetic 65+ & 11,033 & 2,081 & 80.8 & $80.1-81.5$ \\
Diabetic <65 & 2,662 & 348 & 86.1 & $84.7-87.4$ \\
Diabetic 65+ & 2,979 & 619 & 79.0 & $77.5-80.5$ \\
\hline
\end{tabular}

Cohorts of patients alive on $31 / 12 / 2012$

cohort years 2003 to 2012 is shown in this chapter, appendix 1, table 5.25.

\section{Survival in patients with diabetes}

There was a large difference in one year survival between diabetic and non-diabetic prevalent dialysis patients in the younger age group (aged $<65$ years), whereas survival was very similar for older diabetic and non-diabetic patients ( $\geqslant 65$ years) (table 5.14). Similar findings were reported for incident patients (see section on survival in patients with diabetes).

Time trends in patient with a primary diagnosis of diabetes

The age adjusted one year survival for dialysis patients with diabetic primary renal disease in the UK are shown in table 5.15 .

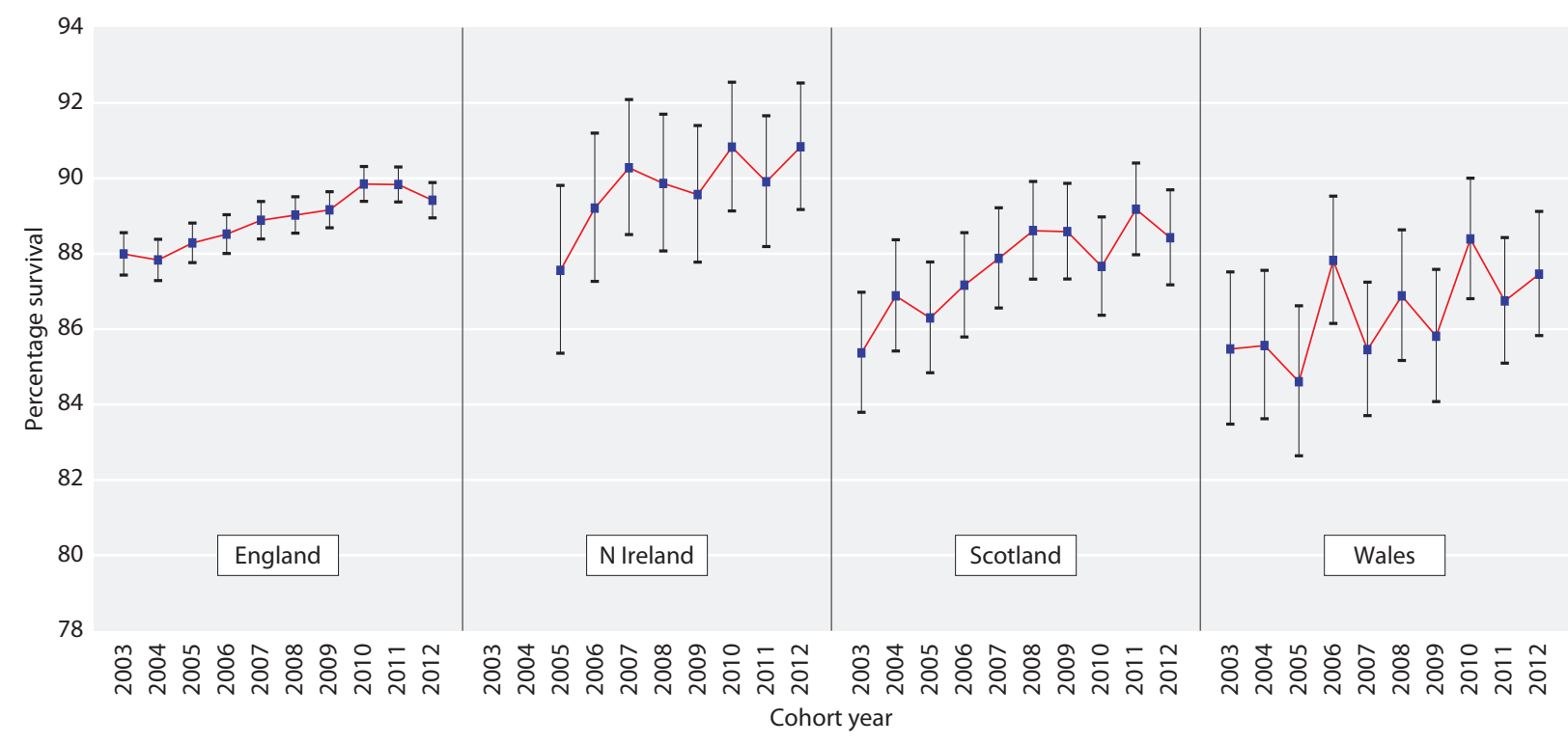

Fig. 5.26. Serial one year survival for prevalent dialysis patients by UK country, 2003 to 2012 cohort years, adjusted to age 60 
Table 5.15. Serial one year survival of prevalent dialysis patients with a primary diagnosis of diabetes, 2003-2012 cohort years

\begin{tabular}{|c|c|c|c|c|c|c|c|c|c|c|}
\hline \multirow[b]{2}{*}{ Survival } & \multicolumn{10}{|c|}{ Year } \\
\hline & 2003 & 2004 & 2005 & 2006 & 2007 & 2008 & 2009 & 2010 & 2011 & 2012 \\
\hline 1 year survival \% & 81.8 & 82.8 & 82.4 & 84.8 & 83.6 & 84.0 & 83.5 & 85.1 & 85.2 & 84.6 \\
\hline
\end{tabular}

\section{Death rate on RRT compared with the UK general population}

The death rate compared to the general population is shown in table 5.16. The relative risk of death on RRT decreased with age from 16.2 times that of the general population at age 35-39 years to 2.6 times the general population at age 85 and over. Figure 5.27 shows that the relative risk of death has decreased substantially for the younger age groups $(<50$ years) compared to the relative risk of death in the 1998-2001 cohort. The overall relative risk of death at 6.2 in the 2012 cohort is similar to that in the 2011 and 2010 cohort. With the reduction in rates of death on RRT over the last 10 years, the relative risk of death is falling (7.7 in 1998-2001 cohort).

Table 5.16. Death rate by age group for all prevalent RRT patients, 2012 cohort, compared with the general population and with previous analyses in the 1998-2001 cohort

\begin{tabular}{|c|c|c|c|c|c|c|c|c|}
\hline $\begin{array}{l}\text { Age } \\
\text { group }\end{array}$ & $\begin{array}{c}\text { UK } \\
\text { population } \\
\text { mid } 2013 \\
\text { (thousands) }\end{array}$ & $\begin{array}{c}\text { UK } \\
\text { deaths in } \\
2013\end{array}$ & $\begin{array}{c}\text { Death rate } \\
\text { per } 1,000 \\
\text { population }\end{array}$ & $\begin{array}{c}\text { Expected } \\
\text { number of } \\
\text { deaths in UKRR } \\
\text { population }\end{array}$ & $\begin{array}{l}\text { UKRR } \\
\text { deaths in } \\
2013\end{array}$ & $\begin{array}{c}\text { UKRR death } \\
\text { rate per } 1,000 \\
\text { prevalent } \\
\text { RRT patients }\end{array}$ & $\begin{array}{l}\text { Relative } \\
\text { risk of } \\
\text { death in } \\
2013\end{array}$ & $\begin{array}{l}\text { Relative } \\
\text { risk of death } \\
\text { 1998-2001 } \\
\text { cohort }\end{array}$ \\
\hline $20-24$ & 4,313 & 1,496 & 0.3 & 0 & 15 & 15 & 44.4 & 41.1 \\
\hline $25-29$ & 4,350 & 1,996 & 0.5 & 1 & 13 & 9 & 18.5 & 41.8 \\
\hline $30-34$ & 4,327 & 2,782 & 0.6 & 1 & 32 & 15 & 22.7 & 31.2 \\
\hline 35-39 & 3,967 & 3,807 & 1.0 & 3 & 43 & 16 & 16.2 & 26.0 \\
\hline $40-44$ & 4,496 & 6,413 & 1.4 & 6 & 109 & 26 & 18.1 & 22.6 \\
\hline $45-49$ & 4,687 & 9,728 & 2.1 & 11 & 165 & 31 & 14.8 & 19.0 \\
\hline 50-54 & 4,344 & 13,759 & 3.2 & 18 & 223 & 38 & 12.1 & 12.8 \\
\hline 55-59 & 3,757 & 19,026 & 5.1 & 29 & 335 & 59 & 11.6 & 10.1 \\
\hline $60-64$ & 3,541 & 28,361 & 8.0 & 45 & 442 & 79 & 9.9 & 10.4 \\
\hline 65-69 & 3,491 & 42,380 & 12.1 & 69 & 596 & 105 & 8.6 & 7.9 \\
\hline $70-74$ & 2,539 & 52,165 & 20.5 & 97 & 690 & 147 & 7.1 & 7.2 \\
\hline $75-79$ & 2,092 & 72,499 & 34.7 & 135 & 787 & 203 & 5.9 & 5.3 \\
\hline 80-84 & 1,550 & 96,885 & 62.5 & 155 & 675 & 272 & 4.3 & 4.0 \\
\hline $85+$ & 1,459 & 219,977 & 150.8 & 172 & 444 & 389 & 2.6 & 3.0 \\
\hline Total & 48,913 & 571,274 & 11.7 & 742 & 4,569 & 88 & 6.2 & 7.7 \\
\hline
\end{tabular}

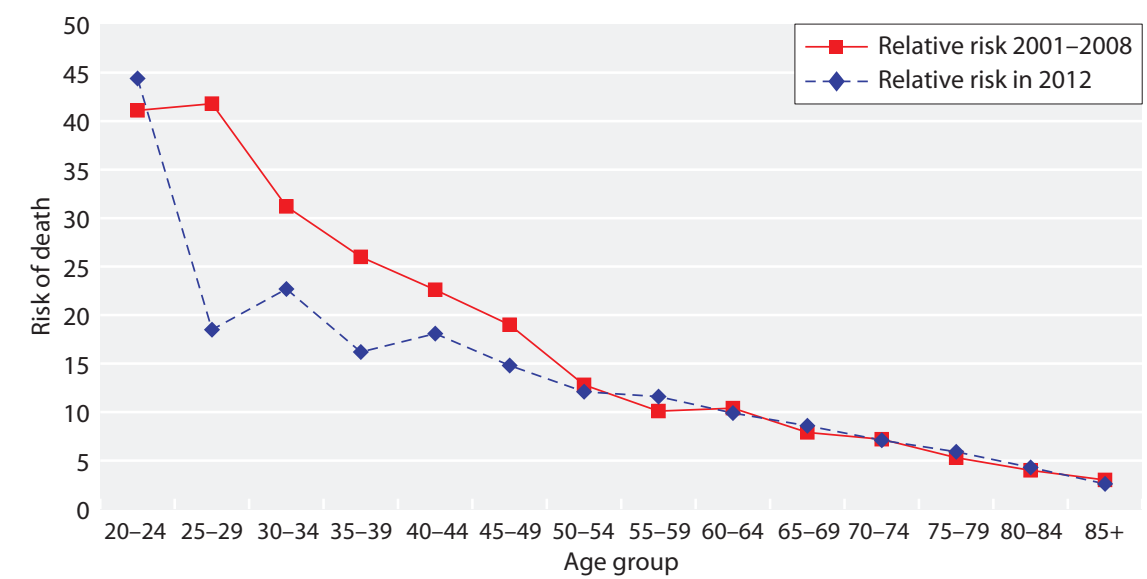

Fig. 5.27. Relative risk of death in prevalent RRT patients in the 2012 cohort compared to the UK general population 


\section{Cause of death}

\section{Data completeness}

Completeness of cause of death data was $70.0 \%$ in 2013 (see appendix 1, table 5.26). A large improvement of $35 \%$ in the completeness of cause of death data for Wales, contributed to the overall UK improvement of $2.2 \%$ in 2013 (appendix 1, table 5.26). Some centres consistently achieve a very high rate of data return for cause of death because a process is in place to ensure that these data were entered. Several centres have shown substantial improvement in data returns (appendix 1, table 5.26), but there was still much variability between the centres regarding the completeness of cause of death with some centres returning no data and other centres having $100 \%$.

\section{Cause of death in incident RRT patients}

Cause of death within the first 90 days

See table 5.17 .
Cause of death within one year after 90 days

Treatment withdrawal as a cause of death (tables 5.17, 5.18 ) in incident patients in the first 90 days and one year after 90 days was more common in older patients (aged $65+$ ) and malignancy more common in younger patients ( $<65$ years old). Infection as cause of death within the first 90 days was more common in older patients. Cardiac disease remained the leading cause of death both in the first 90 days and one year after 90 days. Treatment withdrawal as cause of death at 90 days has increased in older patients (aged 65+) during the last three years (data not shown).

Cause of death in prevalent RRT patients in the 2012 cohort

Table 5.19 shows the cause of death for both prevalent dialysis and transplant patients in the 2012 cohort. These data are neither age adjusted nor adjusted for differences in the comorbidity between the two groups. Cardiac

Table 5.17. Cause of death in the first 90 days for incident patients by age group, 2000-2012 cohort

\begin{tabular}{|c|c|c|c|c|c|c|}
\hline \multirow[b]{2}{*}{ Cause of death } & \multicolumn{2}{|c|}{ All age groups } & \multicolumn{2}{|c|}{$<65$ years } & \multicolumn{2}{|c|}{$\geqslant 65$ years } \\
\hline & $N$ & $\%$ & $N$ & $\%$ & $N$ & $\%$ \\
\hline Cardiac disease & 717 & 26 & 171 & 29 & 546 & 26 \\
\hline Cerebrovascular disease & 132 & 5 & 30 & 5 & 102 & 5 \\
\hline Infection & 480 & 18 & 88 & 15 & 392 & 18 \\
\hline Malignancy & 253 & 9 & 75 & 13 & 178 & 8 \\
\hline Treatment withdrawal & 414 & 15 & 56 & 9 & 358 & 17 \\
\hline Other & 625 & 23 & 155 & 26 & 470 & 22 \\
\hline Uncertain & 115 & 4 & 23 & 4 & 92 & 4 \\
\hline Total & 2,736 & & 598 & & 2,138 & \\
\hline No cause of death data & 2,582 & 49 & 570 & 49 & 2,012 & 48 \\
\hline
\end{tabular}

Table 5.18. Cause of death at one year after 90 days for incident patients by age group, 2000-2012 cohort

\begin{tabular}{|c|c|c|c|c|c|c|}
\hline \multirow[b]{2}{*}{ Cause of death } & \multicolumn{2}{|c|}{ All age groups } & \multicolumn{2}{|c|}{$<65$ years } & \multicolumn{2}{|c|}{$\geqslant 65$ years } \\
\hline & $N$ & $\%$ & $N$ & $\%$ & $N$ & $\%$ \\
\hline Cerebrovascular disease & 251 & 5 & 69 & 5 & 182 & 5 \\
\hline Infection & 921 & 18 & 258 & 18 & 663 & 18 \\
\hline Malignancy & 543 & 11 & 181 & 13 & 362 & 10 \\
\hline Uncertain & 274 & 5 & 83 & 6 & 191 & 5 \\
\hline Total & 5,026 & & 1,413 & & 3,613 & \\
\hline No cause of death data & 4,563 & 47.6 & 1,285 & 47.6 & 3,278 & 47.6 \\
\hline
\end{tabular}


Table 5.19. Cause of death in prevalent RRT patients by modality, 2012 cohort

\begin{tabular}{|c|c|c|c|c|c|c|}
\hline \multirow[b]{2}{*}{ Cause of death } & \multicolumn{2}{|c|}{ All modalities } & \multicolumn{2}{|c|}{ Dialysis } & \multicolumn{2}{|c|}{ Transplant } \\
\hline & $N$ & $\%$ & $N$ & $\%$ & $N$ & $\%$ \\
\hline Cerebrovascular disease & 136 & 4 & 111 & 4 & 25 & 5 \\
\hline Infection & 664 & 21 & 531 & 20 & 133 & 26 \\
\hline Malignancy & 311 & 10 & 186 & 7 & 125 & 24 \\
\hline Uncertain & 186 & 6 & 161 & 6 & 25 & 5 \\
\hline Total & 3,216 & & 2,696 & & 520 & \\
\hline No cause of death data & 1,353 & 30 & 1,130 & 30 & 223 & 30 \\
\hline
\end{tabular}

Table 5.20. Cause of death in prevalent transplanted patients by age group, 2012 cohort

\begin{tabular}{|c|c|c|c|c|c|c|}
\hline Cause of death & \multicolumn{2}{|c|}{ All age groups } & \multicolumn{2}{|c|}{$<65$ years } & \multicolumn{2}{|c|}{$\geqslant 65$ years } \\
\hline Cerebrovascular disease & 25 & 5 & 11 & 4 & 14 & 5 \\
\hline Infection & 133 & 26 & 65 & 25 & 68 & 27 \\
\hline Malignancy & 125 & 24 & 73 & 28 & 52 & 20 \\
\hline Uncertain & 25 & 5 & 9 & 3 & 16 & 6 \\
\hline Total & 520 & & 264 & & 256 & \\
\hline No cause of death data & 223 & 30 & 110 & 29 & 113 & 31 \\
\hline
\end{tabular}

disease as a cause of death was less common in transplanted patients as these were a pre-selected low risk group of patients. Malignancy and infection were both responsible for a greater percentage of deaths in prevalent transplanted patients, with treatment withdrawal a common cause of death in the prevalent dialysis population.

Table 5.20 shows that malignancy and cardiac disease were slightly more common in younger ( $<65$ years) prevalent transplanted patients as the cause of death than in older ( $\geqslant 65$ years old) transplanted patients.

Table 5.21 shows the cause of death for prevalent dialysis patients in the 2012 cohort. Prevalent dialysis patients aged $\geqslant 65$ years were substantially more likely to withdraw from treatment than younger patients and cardiac disease was much more common as a cause of death in younger ( $<65$ years) dialysis patients. Figure 5.28

Table 5.21. Cause of death in prevalent dialysis patients by age group, 2012 cohort

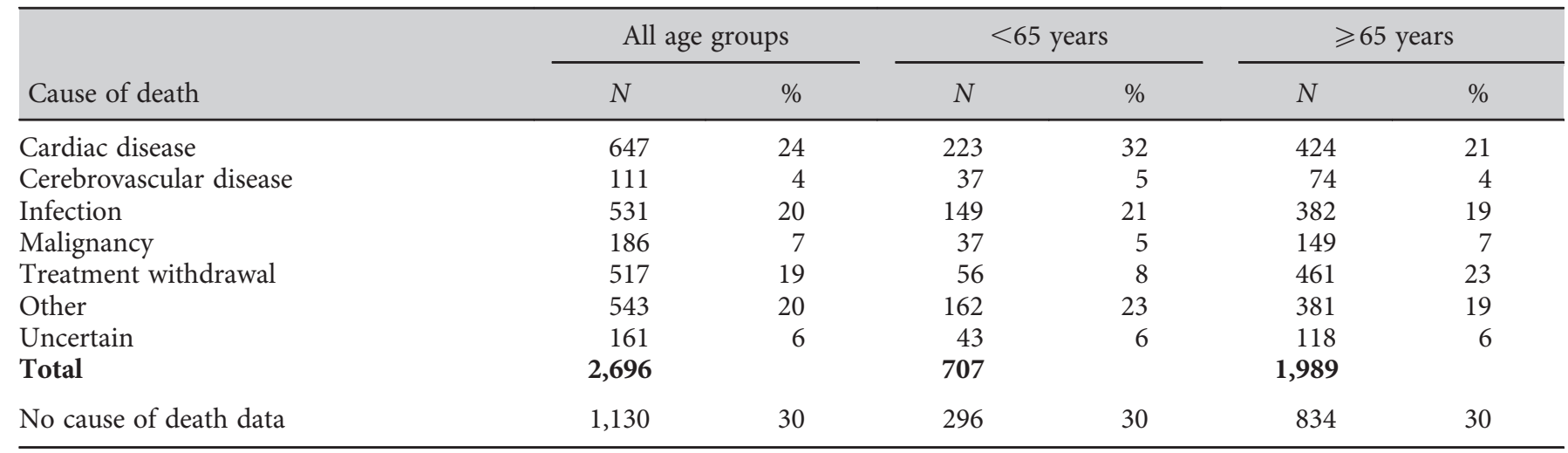




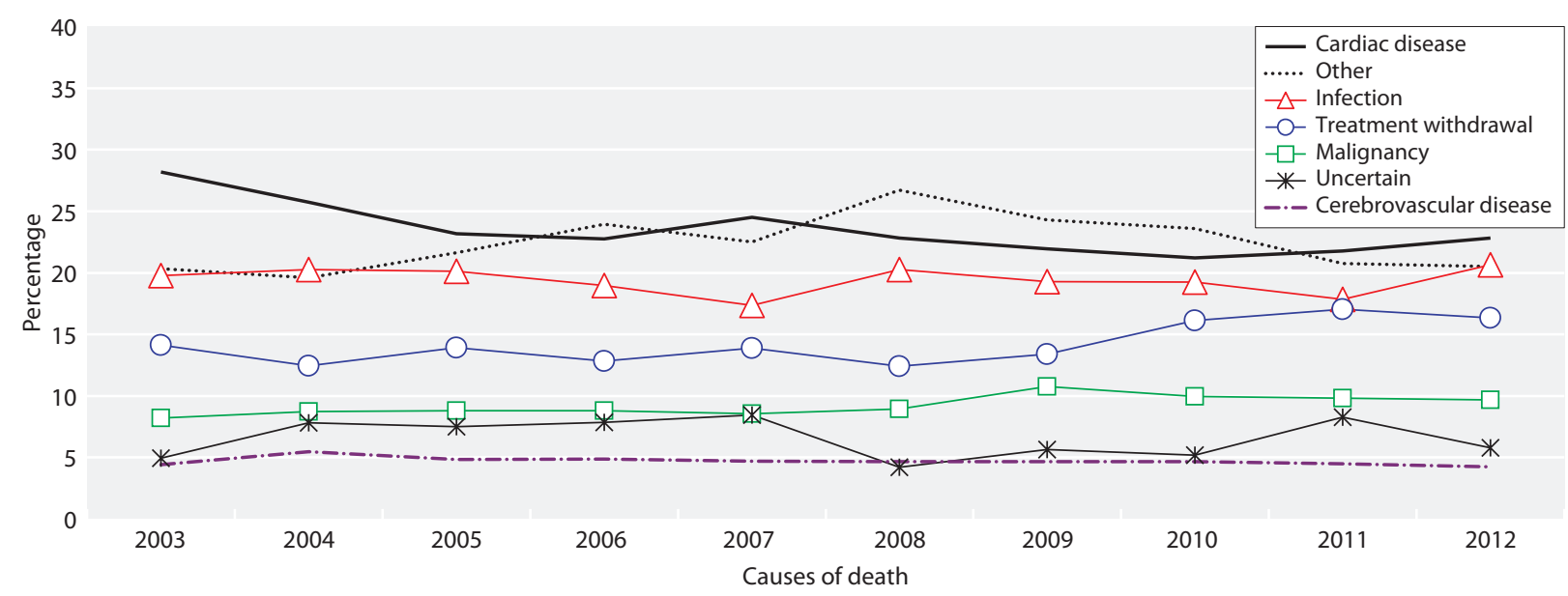

Fig. 5.28. Cause of death in prevalent RRT patients by cohort year

shows cause of death for prevalent patients in the 2003 to 2012 cohort. Over time, cardiovascular disease as cause of death has decreased markedly; treatment withdrawal has increased over time, while infection as cause of death remained at a high level over this period (figure 5.27).

\section{Conclusions}

One year after 90 days age adjusted (adjusted to age 60) survival for incident RRT patients improved over the last 10 years (2003 to 2012 cohorts), although survival in the 2012 cohort remained relatively unchanged at $91.0 \%$ compared to $90.9 \%$ for those patients starting RRT in 2011. Prevalent dialysis patient survival remained static over the last three years (2010 to 2012 cohort).

One year after 90 day survival in incident patients with diabetes aged $\geqslant 65$ years, was better compared to nondiabetic patients, whereas in younger (aged $<65$ years) incident patients with diabetes, survival was worse compared to non-diabetic patients. The relative risk of death on RRT decreased with age from 16.2 times that of the general population at age 35-39 years to 2.6 times the general population at age 85 and over.

In the prevalent RRT population, cardiovascular disease accounted for $27 \%$ of deaths, infection and other causes of death accounted for $21 \%$ of deaths each and treatment withdrawal for $16 \%$ of deaths. Since 2003 , infection as cause of death remained high and treatment withdrawal as cause of death increased.

There was much variability in survival between centres, with outlying centres below the lower 95\% and 99\% confidence limits for incident RRT and prevalent dialysis patient survival. The survival analyses in this chapter have not been adjusted for any case-mix factors except for age, and differences in primary renal diagnosis, ethnicity, comorbidity and life expectancy in the general population have not been considered.

Research has suggested that adjustment for comorbidity only explains a modest part of the variance in ERF patient outcomes [10]. At centre level however, the prevalence of comorbidities could vary substantially between patient populations of the different renal centres and it would be expected that adjustment for comorbidity may explain an increased amount of the variance in survival outcome. An incident patient analysis evaluating the effect of adjusting for PRD and comorbidity in addition to age in those centres returning $\geqslant 85 \%$ of comorbidities, showed that at centre level, there is clear benefit in some centres when adjusting for PRD and comorbidities. Research using comorbid conditions identified from the HES data, illustrated that adjusting for HES derived case-mix, including comorbid conditions, affected the position and outlying status of some renal centres on the funnel plot for incident patients and reduced outlying centres from four to one [11]. Variation in the proportion of patients with terminal illness receiving RRT between centres could also contribute to variations in survival and provide a possible explanation for lower survival than expected for some centres. Survival adjusted for case-mix (age, ethnicity, PRD and comorbidity) will be introduced in future UKRR reports and this will provide a fairer comparison of centres and a more accurate identification of outlying centres on the funnel plots.

Conflicts of interest: none 


\section{References}

1 Plantinga LC, Fink NE, Levin NW, et al.: Early, Intermediate, and LongTerm Risk Factors for Mortality in Incident Dialysis Patients: The Choices for Healthy Outcomes in Caring for ESRD (CHOICE) Study. American journal of kidney diseases: the official journal of the National Kidney Foundation 2007;49(6):831-40

2 Miskulin DC, Meyer KB, Martin AA, et al.: Comorbidity and its change predict survival in incident dialysis patients. American journal of kidney diseases: the official journal of the National Kidney Foundation 2003;41(1):149-61

3 Nitsch D, Burden R, Steenkamp R, Ansell D, Byrne C, Caskey F, et al.: Patients with diabetic nephropathy on renal replacement therapy in England and Wales. Qjm-an International Journal of Medicine 2007 Sep;100(9):551-60

4 Roderick P, Byrne C, Casula A, Steenkamp R, Ansell D, Burden R, et al.: Survival of patients from South Asian and Black populations starting renal replacement therapy in England and Wales. Nephrology Dialysis Transplantation 2009 Dec;24(12):3774-82

5 Tomson C, Maggs C: UK Renal Registry 12th Annual Report (December 2009): Chapter 2: introduction. Nephron Clin Pract 2010;115(suppl 1): c3-8

6 Ford DJ, Fogarty DG, Steenkamp R, Tomson CRV, Ben-Shlomo Y, Ansell D: Chapter 13: The UK Renal Registry Advanced CKD Study: frequency of incorrect reporting of date of start of RRT. Nephron Clinical Practice 115(suppl 1):c271-c78

7 Malek SK, Keys BJ, Kumar S, Milford E, Tullius SG: Racial and ethnic disparities in kidney transplantation. Transplant International 2011; 24(5):419-24 doi: 10.1111/j.1432-2277.2010.01205.x[published Online First: Epub Date]

8 Office for National Statistics: www.ons.gov.uk, http://www.ons.gov.uk/ ons/dcp171778_238743.pdf

9 Ansell D, Roderick P, Hodsman A, Ford D, Steenkamp R, Tomson C: UK Renal Registry 11th Annual Report (December 2008): Chapter 7 Survival and cause of death of UK adult patients on renal replacement therapy in 2007: national and centre-specific analyses. Nephron Clin Pract 2009;111(suppl 1):c113-39

11 Fotheringham J, et al.: Variation in centre-specific survival in patients starting renal replacement therapy in England is explained by enhanced comorbidity information from hospitalization data. Nephrology Dialysis Transplantation 29(2):422-430

10 van Manen JG, van Dijk PCW, Stel VS, Dekker FW, Cleries M, Conte F, et al:: Confounding effect of comorbidity in survival studies in patients on renal replacement therapy. Nephrology Dialysis Transplantation 2007;22(1):187-95 


\section{Appendix 1: Survival tables}

Table 5.22. One year after 90 day incident survival percentage by centre, 2012 cohort, unadjusted and adjusted to age 60

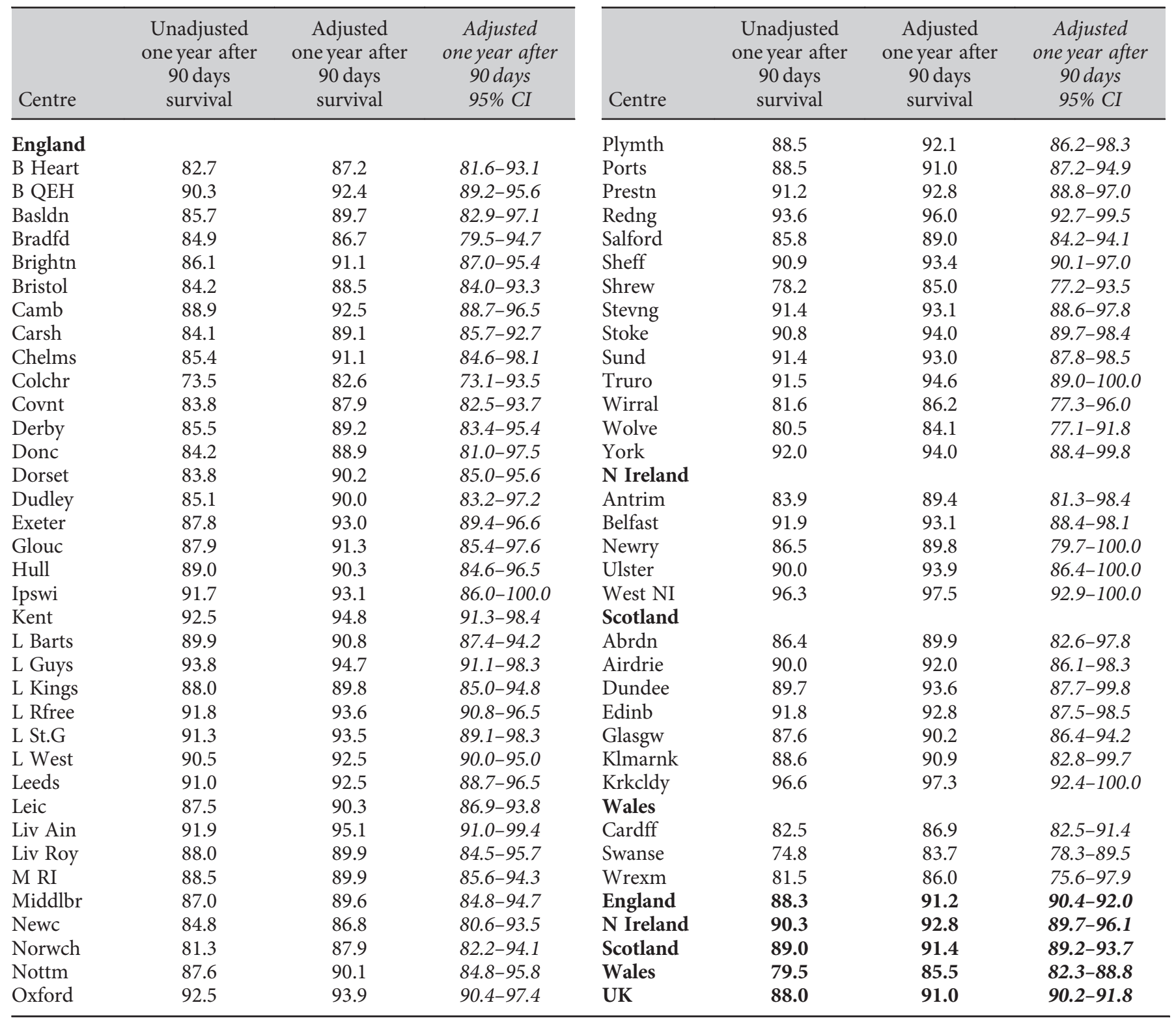

Excluded: centres with less than 20 patients (Bangor, Carlisle, Clwyd, D \& Gall, Inverns, Sthend) 
Table 5.23. Ninety day incident survival percentage by centre, 2012 cohort, unadjusted and adjusted to age 60

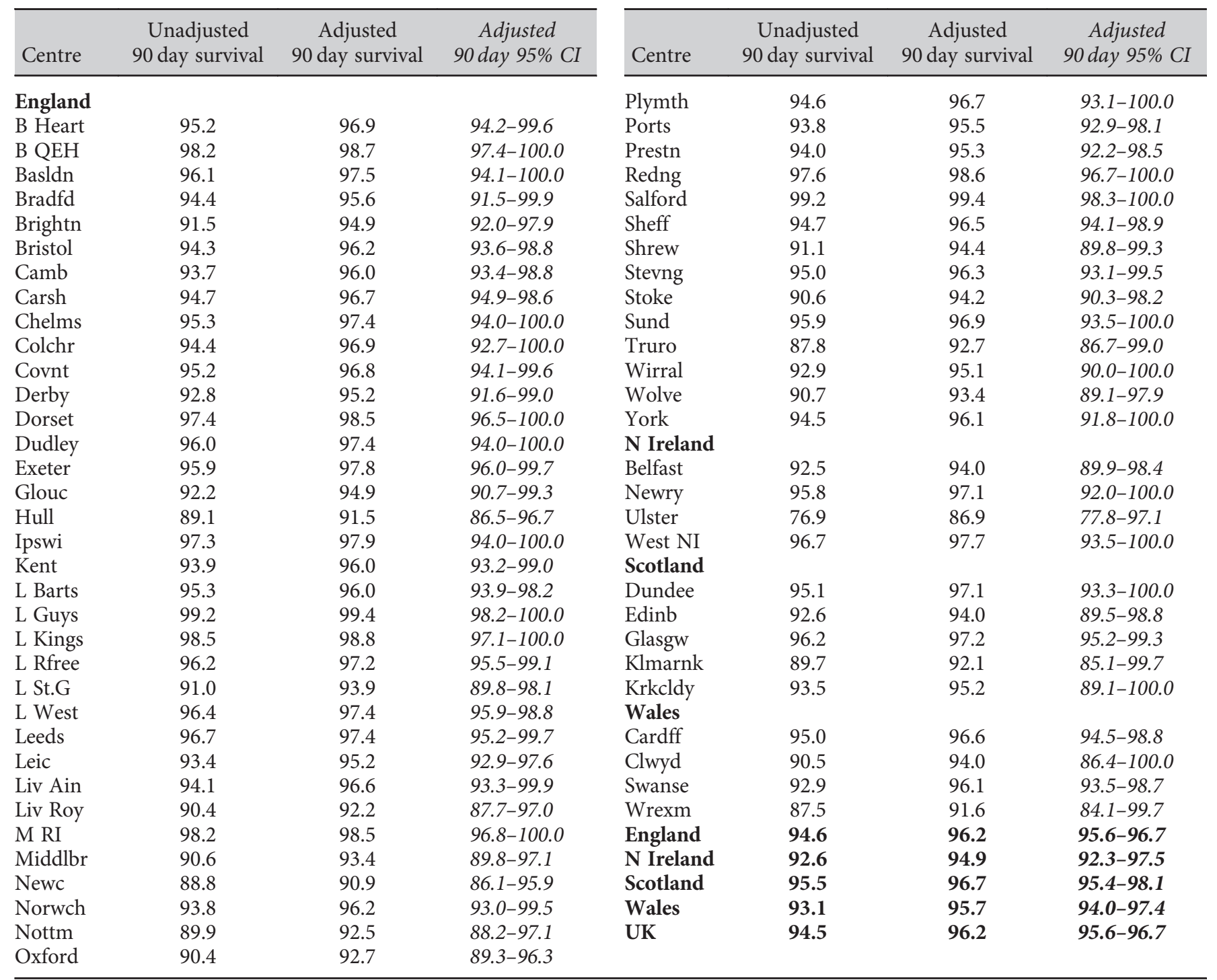

Excluded: centres with less than 20 patients (Carlis, D \& Gall, Inverns, Bangor) and centres with no deaths recorded in the first 90 days of RRT (Donc, Sthend, Antrim, Abrdn, Airdrie) 
Table 5.24. One year after 90 day incident survival by centre for incident cohort years 2003-2012, adjusted to age 60

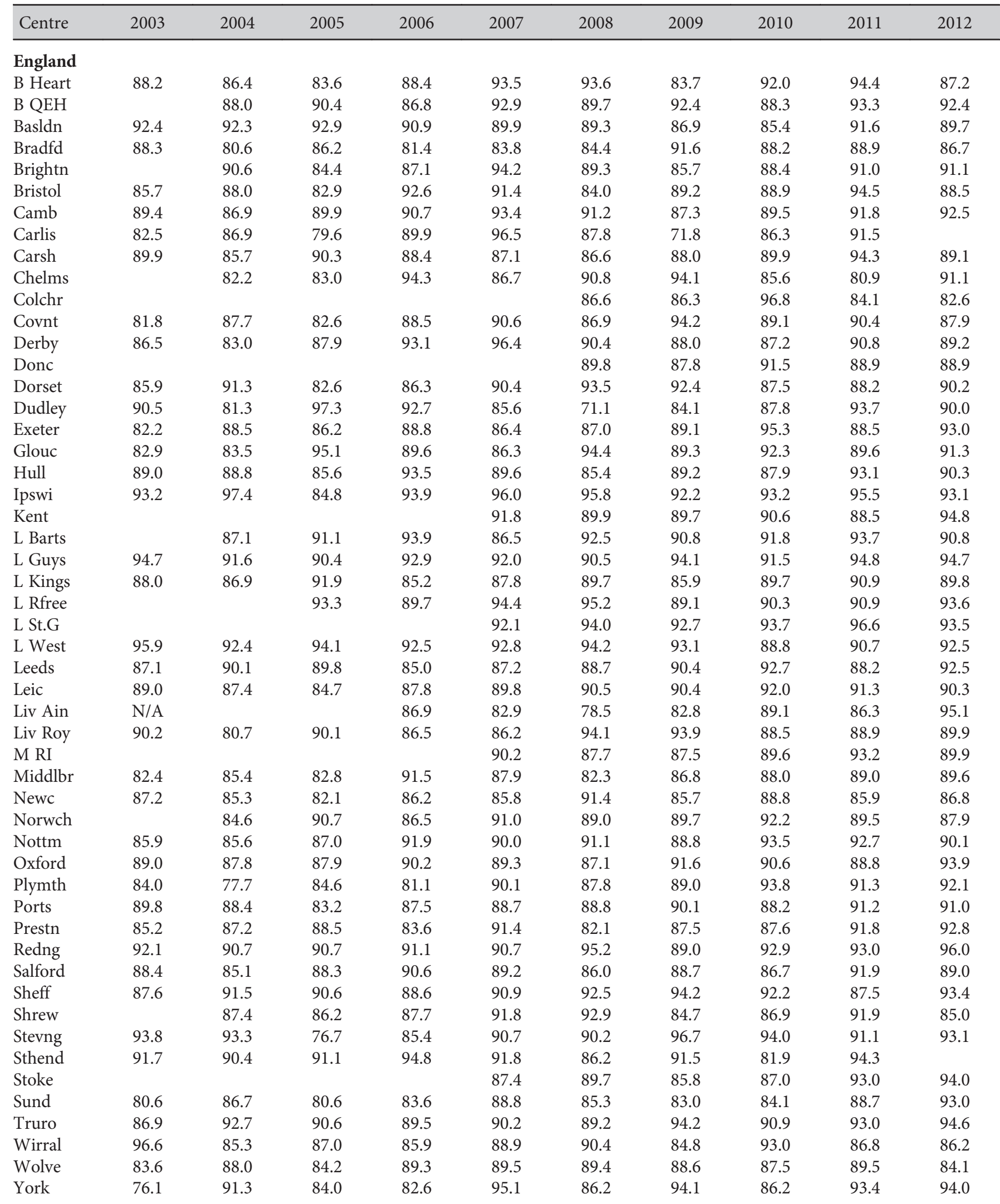


Table 5.24. Continued

\begin{tabular}{|c|c|c|c|c|c|c|c|c|c|c|}
\hline Centre & 2003 & 2004 & 2005 & 2006 & 2007 & 2008 & 2009 & 2010 & 2011 & 2012 \\
\hline Antrim & & & 87.4 & 93.9 & 87.0 & 90.2 & 97.4 & 90.2 & 86.3 & 89.4 \\
\hline Newry & & & 90.2 & & & 90.0 & & 92.0 & 87.9 & 89.8 \\
\hline Ulster & & & & & & & & 90.9 & 86.3 & 93.9 \\
\hline West NI & & & & 90.2 & 97.3 & 93.1 & 97.6 & 91.3 & 95.9 & 97.5 \\
\hline Abrdn & 86.0 & 88.7 & 84.2 & 82.5 & 86.0 & 86.9 & 88.8 & 85.4 & 92.8 & 89.9 \\
\hline Airdrie & 74.6 & 86.1 & 75.2 & 80.7 & 76.7 & 88.3 & 94.3 & 82.0 & 84.1 & 92.0 \\
\hline D \& Gall & 84.5 & & & & & & 84.0 & & & \\
\hline Dundee & 86.9 & 85.7 & 84.4 & 89.4 & 81.4 & 86.2 & 87.9 & 90.3 & 90.3 & 93.6 \\
\hline Edinb & 86.7 & 79.4 & 83.3 & 88.8 & 90.1 & 84.5 & 85.1 & 86.4 & 90.2 & 92.8 \\
\hline Glasgw & 87.4 & 81.0 & 86.3 & 83.4 & 88.1 & 84.2 & 88.7 & 86.9 & 88.6 & 90.2 \\
\hline \multicolumn{11}{|l|}{ Wales } \\
\hline Bangor & 91.1 & 80.8 & 82.3 & 81.4 & 92.3 & 87.8 & 87.3 & 89.1 & 94.3 & \\
\hline Cardff & 87.2 & 85.4 & 87.2 & 87.1 & 84.3 & 83.2 & 89.3 & 89.5 & 88.2 & 86.9 \\
\hline Clwyd & & & & 96.9 & & & 92.3 & & & \\
\hline Swanse & 84.6 & 77.7 & 82.7 & 84.2 & 89.0 & 85.1 & 81.7 & 86.8 & 85.0 & 83.7 \\
\hline Wrexm & 93.5 & 77.2 & 97.7 & 85.5 & 90.0 & & & 82.1 & 88.8 & 86.0 \\
\hline England & 88.4 & 87.8 & 87.9 & 89.0 & 90.2 & 89.5 & 89.8 & 90.0 & 91.1 & 91.2 \\
\hline N Ireland & & & 89.0 & 91.6 & 91.0 & 88.4 & 92.1 & 90.3 & 90.3 & 92.8 \\
\hline Scotland & 86.0 & 84.7 & 84.5 & 84.5 & 86.5 & 86.0 & 87.4 & 87.8 & 90.2 & 91.4 \\
\hline Wales & 87.0 & 82.4 & 86.0 & 86.2 & 86.8 & 84.4 & 87.3 & 88.6 & 87.6 & 85.5 \\
\hline UK & 88.0 & 87.1 & 87.5 & 88.5 & 89.7 & 89.0 & 89.5 & 89.7 & 90.8 & 91.0 \\
\hline
\end{tabular}

Blank cells: centres with less than 20 patients for that year or centres with no data available for that year 
Table 5.25. One year prevalent patient survival by centre for prevalent cohort years 2003-2012, adjusted to age 60

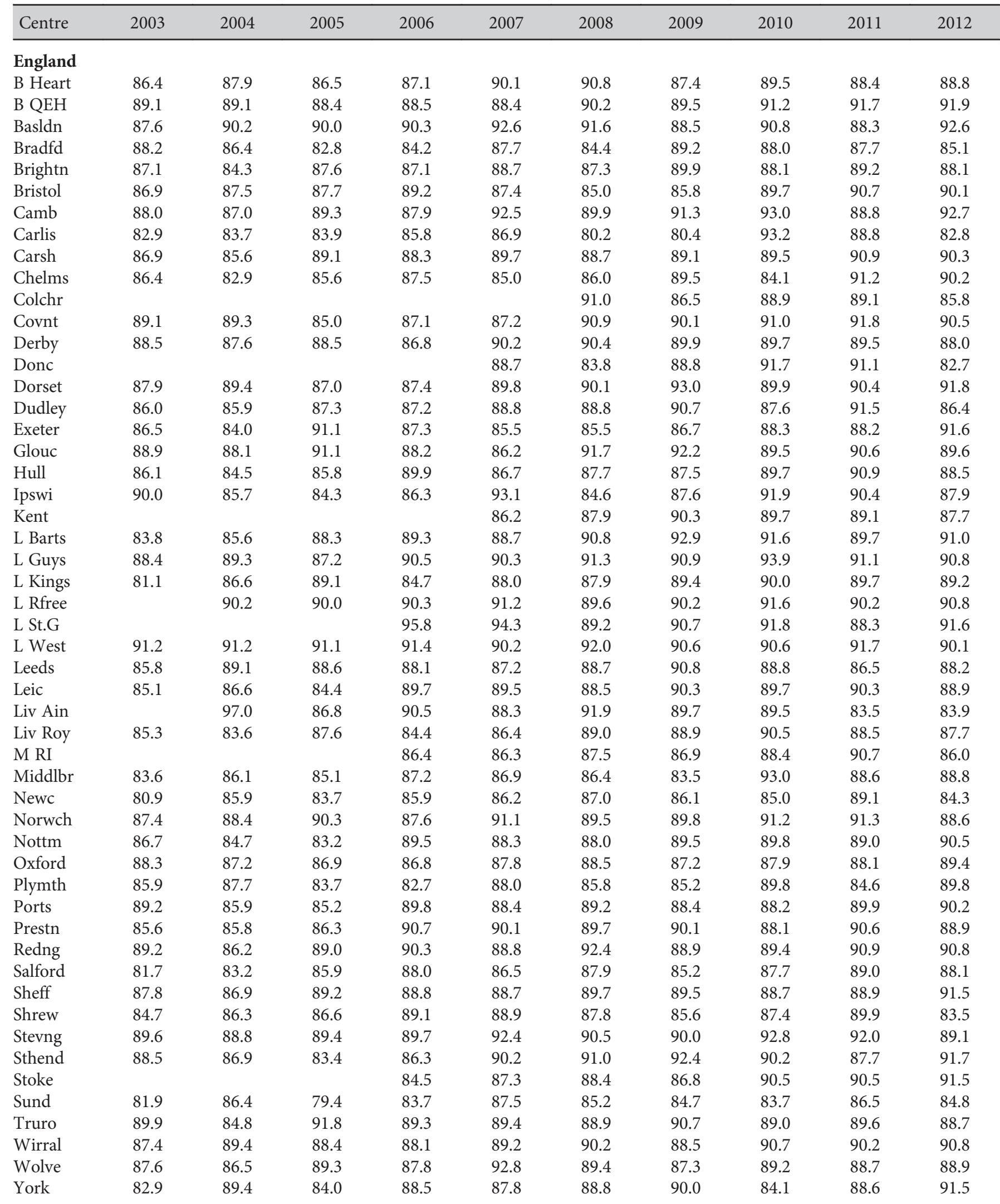


Table 5.25. Continued

\begin{tabular}{|c|c|c|c|c|c|c|c|c|c|c|}
\hline Centre & 2003 & 2004 & 2005 & 2006 & 2007 & 2008 & 2009 & 2010 & 2011 & 2012 \\
\hline \multicolumn{11}{|l|}{ N Ireland } \\
\hline Antrim & & & 92.1 & 85.9 & 89.0 & 90.5 & 89.2 & 92.7 & 91.4 & 92.4 \\
\hline Newry & & & 87.5 & 87.4 & 90.9 & 94.3 & 88.0 & 92.0 & 83.8 & 91.5 \\
\hline Ulster & & & 91.6 & 89.4 & 92.7 & 88.2 & 90.5 & 90.4 & 91.6 & 92.0 \\
\hline West NI & & & 83.7 & 91.0 & 92.9 & 89.7 & 91.8 & 91.0 & 92.2 & 92.6 \\
\hline Abrdn & 85.4 & 87.6 & 86.1 & 87.2 & 89.5 & 89.3 & 89.7 & 89.0 & 90.9 & 88.2 \\
\hline Airdrie & 84.1 & 82.8 & 79.7 & 79.4 & 85.9 & 85.4 & 89.3 & 88.4 & 86.2 & 85.7 \\
\hline D \& Gall & 83.1 & 92.1 & 82.1 & 90.6 & 84.6 & 88.4 & 87.3 & 91.3 & 87.4 & 90.4 \\
\hline Dundee & 85.8 & 87.3 & 87.4 & 83.8 & 83.8 & 93.6 & 87.6 & 88.0 & 91.8 & 89.5 \\
\hline Edinb & 83.9 & 85.5 & 86.6 & 87.8 & 88.3 & 86.1 & 89.1 & 82.4 & 90.2 & 89.8 \\
\hline Glasgw & 85.5 & 87.5 & 86.4 & 88.1 & 88.3 & 88.6 & 88.7 & 88.2 & 88.6 & 88.1 \\
\hline \multicolumn{11}{|l|}{ Wales } \\
\hline Bangor & 89.8 & 86.6 & 88.5 & 81.4 & 88.7 & 85.0 & 85.4 & 86.8 & 89.9 & 84.4 \\
\hline Cardff & 85.0 & 84.3 & 84.1 & 88.7 & 82.4 & 86.4 & 85.8 & 88.2 & 86.2 & 87.5 \\
\hline Clwyd & 74.6 & 82.0 & 77.3 & 90.5 & 87.0 & 88.8 & 78.1 & 93.0 & 89.9 & 86.2 \\
\hline Swanse & 87.0 & 89.0 & 85.4 & 87.9 & 89.4 & 87.2 & 87.4 & 88.9 & 86.1 & 88.3 \\
\hline Wrexm & 85.4 & 82.1 & 85.1 & 87.6 & 85.1 & 88.9 & 86.7 & 85.7 & 87.2 & 89.2 \\
\hline England & 88.0 & 87.8 & 88.3 & 88.5 & 88.9 & 89.0 & 89.2 & 89.9 & 89.8 & 89.4 \\
\hline N Ireland & & & 87.6 & 89.2 & 90.3 & 89.9 & 89.6 & 90.8 & 89.9 & 90.8 \\
\hline Scotland & 85.4 & 86.9 & 86.3 & 87.2 & 87.9 & 88.6 & 88.6 & 87.7 & 89.2 & 88.4 \\
\hline Wales & 85.5 & 85.6 & 84.6 & 87.8 & 85.5 & 86.9 & 85.8 & 88.4 & 86.7 & 87.5 \\
\hline UK & 87.9 & 87.6 & 87.9 & 88.4 & 88.7 & 88.9 & 89.0 & 89.6 & 89.6 & 89.3 \\
\hline
\end{tabular}

Blank cells: data not reported for that year or less than 20 patients in the year 
Table 5.26. Percentage completeness of EDTA cause of death for prevalent patients by centre and year of death, 2004 to 2013

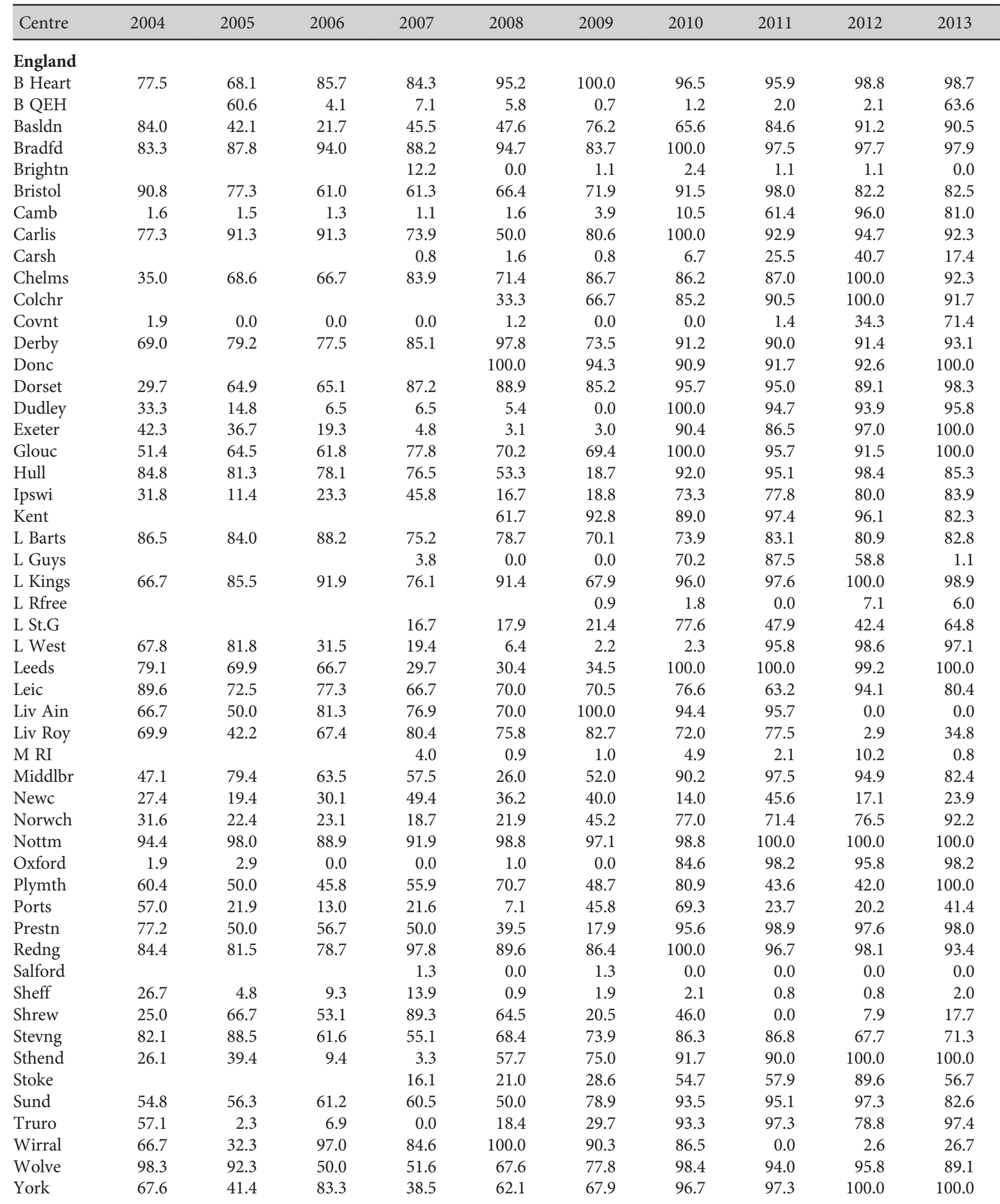


Table 5.26. Continued

\begin{tabular}{|c|c|c|c|c|c|c|c|c|c|c|}
\hline Centre & 2004 & 2005 & 2006 & 2007 & 2008 & 2009 & 2010 & 2011 & 2012 & 2013 \\
\hline \multicolumn{11}{|l|}{ N Ireland } \\
\hline Antrim & & & 10.0 & 8.8 & 3.7 & 28.0 & 96.8 & 95.2 & 100.0 & 100.0 \\
\hline Newry & & & 42.9 & 15.0 & 13.3 & 81.3 & 95.2 & 100.0 & 96.7 & 100.0 \\
\hline Ulster & & & 85.7 & 92.9 & 90.0 & 75.0 & 95.0 & 95.2 & 100.0 & 100.0 \\
\hline West NI & & & 57.7 & 36.8 & 23.5 & 45.8 & 96.0 & 83.3 & 100.0 & 95.8 \\
\hline Abrdn & 35.0 & 0.0 & 0.0 & 2.1 & 100.0 & 100.0 & 100.0 & 100.0 & 100.0 & 100.0 \\
\hline Airdrie & 34.5 & 42.4 & 26.3 & 100.0 & 100.0 & 100.0 & 100.0 & 100.0 & 100.0 & 100.0 \\
\hline D \& Gall & 100.0 & 80.0 & 76.9 & 100.0 & 100.0 & 100.0 & 100.0 & 100.0 & 100.0 & 100.0 \\
\hline Dundee & 92.1 & 86.1 & 2.8 & 9.1 & 100.0 & 100.0 & 100.0 & 100.0 & 100.0 & 100.0 \\
\hline Edinb & 51.7 & 50.8 & 29.3 & 47.5 & 100.0 & 100.0 & 100.0 & 100.0 & 100.0 & 100.0 \\
\hline Glasgw & 49.6 & 43.8 & 55.1 & 59.2 & 100.0 & 100.0 & 100.0 & 100.0 & 100.0 & 100.0 \\
\hline \multicolumn{11}{|l|}{ Wales } \\
\hline Bangor & 44.4 & 66.7 & 35.0 & 86.2 & 57.9 & 80.0 & 73.9 & 90.0 & 100.0 & 100.0 \\
\hline Cardff & 2.6 & 4.3 & 2.9 & 4.1 & 0.0 & 2.4 & 6.8 & 8.1 & 0.6 & 74.0 \\
\hline Clwyd & & 5.9 & 11.1 & 45.5 & 84.2 & 83.3 & 100.0 & 85.7 & 89.5 & 83.3 \\
\hline Swanse & 92.9 & 87.9 & 92.4 & 97.3 & 96.0 & 89.8 & 98.0 & 88.6 & 98.1 & 97.8 \\
\hline Wrexm & 3.7 & 3.6 & 4.0 & 25.0 & 69.2 & 100.0 & 95.7 & 96.2 & 100.0 & 95.7 \\
\hline England & 53.8 & 48.4 & 42.2 & 38.6 & 37.3 & 39.2 & 59.3 & 64.1 & 65.2 & 65.6 \\
\hline N Ireland & & & 39.0 & 32.8 & 21.7 & 42.5 & 90.4 & 87.0 & 91.1 & 79.5 \\
\hline Scotland & 50.7 & 42.0 & 33.7 & 44.4 & 100.0 & 100.0 & 100.0 & 100.0 & 100.0 & 100.0 \\
\hline Wales & 31.0 & 28.9 & 31.2 & 43.9 & 36.4 & 47.8 & 53.7 & 49.5 & 50.8 & 86.0 \\
\hline UK & 51.7 & 45.5 & 40.5 & 39.3 & 42.7 & 45.3 & 63.4 & 67.3 & 67.8 & 70.0 \\
\hline
\end{tabular}

Blank cells: data not available for that year 